\title{
Energy Reduction, Daylight and View Quality Assessment of a Passive Dynamic Facade in Hot Arid Climate
}

\author{
Kifah Alhazzaa \\ Lecturer, Faculty of Department of Architecture, College of Architecture and Planning, Qassim University, Buraidah, \\ Alqassim region, Saudi Arabia (Principal contact for editorial correspondence), Email: Arch,Kifah@gmail.com \\ Graduate student, Department of Architecture, College of Architecture, Planning and Landscape Architecture, University of \\ Arizona, Tucson, Arizona
}

\section{Abstract Purpose}

This research aims to create a passive dynamic system with immediate responses to environmental conditions without needing an energy source to operate and reduce operation and maintenance costs.

\section{Design/Methodology/Approach}

There has been growing awareness in recent years of the energy consumption and interior environmental comfort of buildings. Substantial evaluation of the building envelope and indoor human experience is required to develop sustainable solutions, create a responsive system that enhances building performance and human comfort in terms of energy consumption and daylight quality. In this paper, a new proposed advanced integrated façade called a passive dynamic shading device (PDSD) is revealed. The system is designed to contribute to energy reduction, daylight availability, and view quality through its ability to change position and placement to respond and adapt to new climate conditions. The thermal expansion phenomenon was used in the actuation process, with heat-activated actuators that correspond to specific dry-bulb temperatures. This paper concisely demonstrates the functional mechanism and performance of the PDSD. Sophisticated energy and daylight simulations have been executed to distinguish between three case studies. Each case represents one architectural option: 1- without shading devices. 2- with conventional fix shading devices. 3- PDSD.

\section{Findings}

The result shows the PDSD can efficiently reduce overall energy consumption by up to 50\%, increase the amount and quality of daylight by up to $60 \%$ compared to fixed shading devices, and obstruct the view from the interior $22 \%$ of the year.

\section{Research Limitations/Implications}

The limitation was with the thermal expansion mechanism since it expands due to the rise of temperature, which led to system movement in the ineffective time of a day.

\section{Social/Practical Implications}

The study is Creating a new affordable dynamic system comparing with an active dynamic façade system. The system is applicable on any building scale with simple construction.

Originality/Value

Unlike other dynamic façade system studies, in this study, the goal is to create a new passive system using the thermal expansion phenomenon and evaluate its effectiveness on energy reduction, daylight availability, and view quality.

Keywords: Dynamic façade, kinetic façade, thermal actuation, thermal actuator, thermal expansion. 


\section{INTRODUCTION}

In the twentieth century, energy consumption abruptly increased due to urban sprawl, resulting in more commuting [1] and housing [2]. Also, creating the need for essential infrastructure such as public transportation, roads, and streetlights. Another reason has been economic growth to meet increasing demand from consumers due to Population growth. These two factors (i.e., increased urban sprawl and economic growth), contribute to global environmental problems, including the greenhouse effect and the resulting climate change [3].

Conventional understanding of the building envelope is that it serves a barrier between the exterior and interior environments, which is desirable. However, the building envelope is more than this and serves as the foundation for up to $80 \%$ of solutions and strategies aimed at reducing energy consumption and enhancing occupants' experience in terms of thermal and visual comfort, enabling the creation of highperformance buildings that respond to their environment [4]. It plays a significant role in energy efficiency, human thermal and visual comfort, and human psychological wellbeing. The optimum balance of environmental concerns, occupants' comfort, and energy savings can be achieved through innovative building envelopes that are sensitive, interactive, responsive, and adaptive.

This research paper explores the use of actuation energy in building façade technology. The thermal expansion phenomenon is adapted for the actuation process. Creating a passive dynamic façade system is incredibly efficient in terms of initial cost, energy required for operation, and maintenance. The feasibility of implementing such a system in a building is determined by environmental parameters. Performing a daylight analysis and energy simulation in multiple cases with different façade solutions can facilitate assessment of such a system.

Thinking about the day in terms of orientation, each building façade receives direct solar radiation for certain hours. When designing a building, architects can implement fixed shading devices to block direct solar radiation, control glare, and save energy, but based on the orientation of a particular building, these measures are not needed at all points of the day. Ensuring the right amount of daylight in a building is an effective energy-saving strategy and plays a key role in human health and psychological wellbeing. However, this raises the question of whether shading devices that affect the amount of daylight are necessary all day? View quality is an important factor in human psychological wellbeing and the healing process, as scientific research has concluded. Fixed shading devices obstruct views, but it is unreasonable to eliminate them since they serve an important function. However, are they necessary all the time? Using an active dynamic façade addresses the question above. However, it is unclear whether conventional dynamic shading devices can be considered a sustainable 
Energy Reduction, Daylight and View Quality Assessment of a Passive Dynamic Facade in Hot Arid Climate

solution for saving energy since they consume a considerable amount of energy for operations.

\section{LITERATURE REVIEW}

Adaptive building skins is a trending research area in sustainable design that combines active and passive design strategies. According to Rodriguez and Alessandro (2014), the adaptive building skin demonstrates adaptability, transformability, and evolution in the face of different environmental aspects. Jia-Yih and Chu Huang (2016) conducted research on adaptive building façade optimization in Taiwan. They assessed two transformation modes, namely opening shutters (A) and tilting blinds (B), both of which had the same defined parameters and evaluation platform (EnvLoad Evaluation Platform). The results demonstrate that based on the energy required for controlling the opening rate of the shutters, case (A) is a more effective shading design strategy than controlling the shading coefficient value in case (B). [5]

Bacha and Bourbia (2019) created a computational framework to optimize varieties of shading design as a second skin formed by direct solar radiation and daylight utilization parameters. The Ecotect and Radiance platforms are simulation tools used to assess shading system in terms of radiation exposure, daylight utilization, and energy consumption. Such a system has been implemented in a glass office building in the city of Biskra located in the south-eastern part of Algeria, which is considered a hot, arid region. The results indicate direct solar radiation exposure decreased by $17.9 \%$, energy consumption was reduced by $43 \%$, and indoor air temperature was reduced between $4.0^{\circ} \mathrm{C}$ and $4.8^{\circ} \mathrm{C}$. The researchers also integrated photovoltaic cells that generate $6,000 \mathrm{Kw} /$ month into the design [6].

Ahmed, Abdel-Rahman, Bady, and Mahrous (2016) conducted a field study to experiment with a kinetic shading system. The study was conducted between July 20 to August 20 of 2015 in New Borg El-Arab in Alexandria, Egypt $\left(30.9^{\circ} \mathrm{N}, 29.6^{\circ} \mathrm{E}\right)$. The experimental case is the southoriented fenestration of an apartment located on the third floor. Other apartments with the same properties in terms of dimensions, HVAC system, equipment, building envelope, and orientation were used for comparison. The system moved vertically, powered by two servo motors using a direct current as the source of actuation energy. The actuators were monitored by an Arduino microcontroller board with an outdoor temperature sensor and $28^{\circ} \mathrm{C}$ as the setpoint. The results show a decrease in indoor temperature ranging from $25.5^{\circ} \mathrm{C}$ to $35^{\circ} \mathrm{C}$ as the baseline to $25.5^{\circ} \mathrm{C}$ to $28.2^{\circ} \mathrm{C}$ after installing the proposed system. The results demonstrate how the system can enhance human thermal comfort and reduce energy consumption by 15 to $20 \mathrm{~W} / \mathrm{m} 2$ of direct solar radiation [7]. 
Elghazi, Wagdy, and Abdalwahab (2015) investigated an origami-based façade design controlled by daylight performance. The Daysim and Radiance platforms, which are daylight simulation tools, were used to control daylight uniformity. The researchers considered a hypothetical indoor office space with an area of $20 \mathrm{~m} 2$ located in Aswan, Egypt $\left(24^{\circ} 05^{\prime} \mathrm{N} 32^{\circ} 54^{\prime} \mathrm{E}\right)$, which is classified as having a hot, arid desert climate (Peel et al., 2007). The proposed system was implemented on the south façade of the building. The results show a comparison between a static base case and the proposed dynamic system in terms of hourly spatial daylight autonomy (HsDA) and annual sun exposure (ASE). Thus, the study validated the usefulness of the proposed system since it enhanced the indoor environment through increasing daylight quality [8].

Jayathissa, Schmidli, Hofer, and Schlueter (2016) studied electricity generation and building energy consumption through an adaptive building façade system comprising square copper indium gallium selenide (CIGS) panels with two degrees of rotation freedom. The EnergyPlus platform was used for energy simulation through the DIVA interface. An hourly simulation was run for each dynamic configuration corresponding to the study location of Zurich, Switzerland. The results demonstrate the combination of electricity generation and adaptive shading can compensate for $41 \%$ of energy demand over an entire year for the research base case [9].

\section{RESEARCH METHODOLOGY}

This work assesses the performance in terms of both energy consumption and daylight utilization of fixed conventional shading, PDSDs, and a base case without shading devices. This research employed dynamic simulation for both the energy and daylight parameters to assess thermal actuators' operation, which allows passive, dynamic movement in response to a defined ambient temperature, thus providing indispensable protection from direct solar radiation. The shading design follows multiple performance criteria to assure the applicability and eligibility for the specific location. The Energy Plus and Radiance platforms, whose development was funded by the U.S. Department of Energy's (DOE) Building Technologies Office (BTO), are simulation tools for performance assessment of energy consumption and daylight parameters. They can adapt the dynamic changes during the simulations which makes them suitable for this study. Both can be connected to Rhinoceros, which is a commercial 3D computer graphics and computer-aided design program through DIVAfor-Rhino with Rhino and Grasshopper plug-ins (Figure 1.) 


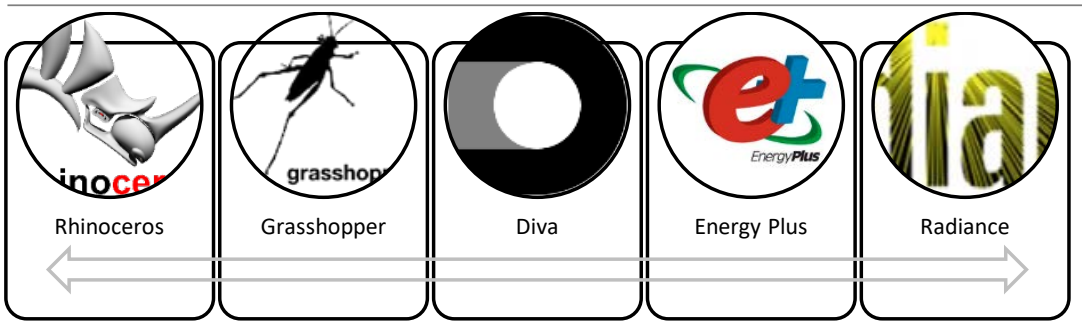

The research makes a consecutive comparison of the three phases documented in Figure 2. Each of the three comparisons measures energy consumption and daylight. The first stage focuses on the base case, which has no shading devices. While this case does not serve as a benchmark for comparison, it determines the value of using shading systems. The second phase analyzes the case with fixed shading devices, and the third analyzes the case with PDSD. An additional step of the third phase is manipulating the PDSD materials to find potential alternatives to enhance performance. The third phase requires a dynamic simulation that is updated on an hourly basis. The Archsim tool, which is a part of DIVA for the Grasshopper plug-in, can create an hourly schedule over the course of a year based on restriction inputs, including environmental climate data. In this research, the dry-bulb temperature, which is extracted from the Energy Plus weather file, drives the PDSD operation schedule. It allows the PDSD to operate accurately in real time based on the data.

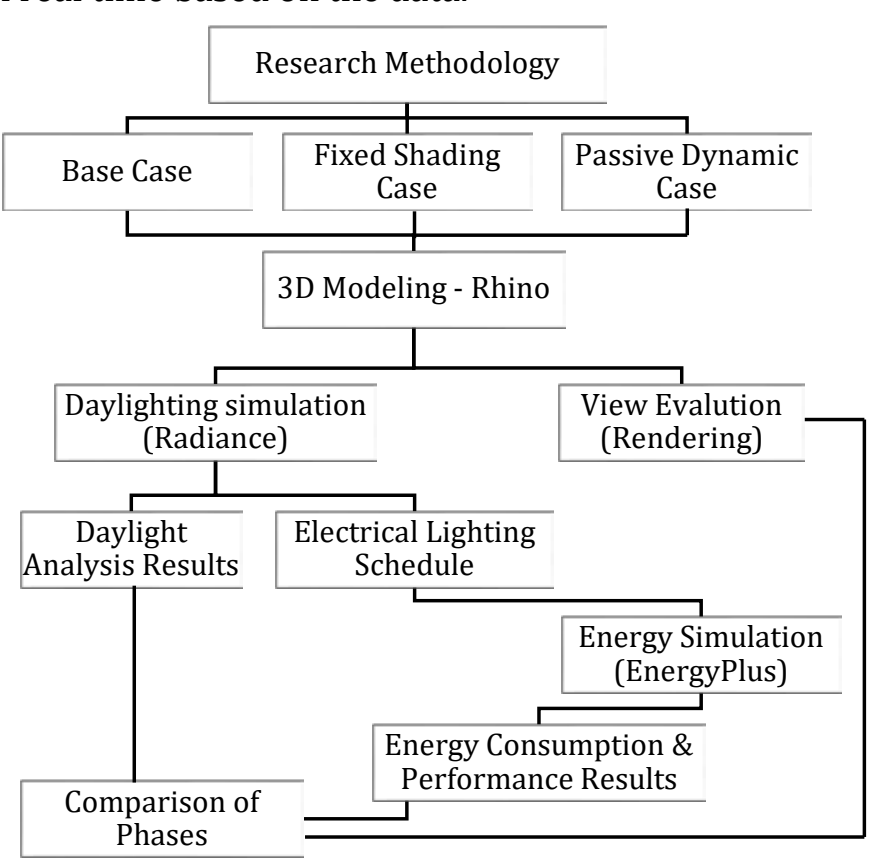

Figure 2. Research methodology diagram 
months have high daytime temperatures between $105^{\circ} \mathrm{F}$ and $115^{\circ} \mathrm{F}$, and the winter months are moderate with temperature generally in the lower 60s. During the three coldest months of winter, nighttime temperatures decrease below freezing, but the afternoons are mostly sunny and warm. January and December have sunshine an average of $78 \%$ of the time. This rises to a maximum of $94 \%$ in June. The yearly average for sunshine is $86 \%$ [10]. According to IECC (Table 1.), Phoenix falls in the 2B climate zone, which is considered hot and dry and has high cooling thermal criteria measured by cooling degree days (CDD) [11].

Table 1. Phoenix's climate characteristics (by IECC)

\begin{tabular}{|c|c|c|c|}
\hline ZONE & TYPE & THERMAL CRITERIA & REPRESENTAT \\
NUMBER & & & IVE U.S. CITY \\
\hline 2B & Hot-Dry & $6300<\mathrm{CDD} 50^{\circ} \mathrm{F}<9000$ & Phoenix, AZ \\
\hline
\end{tabular}

Base Case Design and Properties: The base case of the study is a onestory office building, with applied fixed shading devices and PDSD. The building has open floor plan (figure 3.) and only one window on the west façade (figure 4.). The building meets the minimum requirements of the 2018 City of Phoenix Building Construction Codes (PBCC) in terms of thermal protection. The minimum requirement for this type of building is 19 heat resistance value for walls and 30 for roofs. The building's properties are as follows:

Table 2. Building design and construction characteristics (by author)

\begin{tabular}{|c|c|}
\hline \multicolumn{2}{|l|}{ Building's Properties } \\
\hline Dimensions: $25 \mathrm{ft} \times 14 \mathrm{ft}$ & Floor finish material: Exposed concrete \\
\hline Floor area: 350 sq. $\mathrm{ft}$ & West façade area: $225 \mathrm{ft}^{2}$ \\
\hline Ceiling high: $9 \mathrm{ft}$ & $\begin{array}{l}\text { Window area: } 32 \mathrm{ft}^{2}=14 \% \text { of the west } \\
\text { façade }\end{array}$ \\
\hline Ceiling type: Exposed & Window dimensions: $8 \mathrm{ft}$ x $4 \mathrm{ft}$ \\
\hline Wall construction: Metal frame, R19 & $\begin{array}{l}\text { Window construction: Aluminum frame } \\
\text { with single glazing }\end{array}$ \\
\hline Wall exterior finish material: Stucco & Window orientation: West \\
\hline Roof construction: Metal deck, R30 & Equipment: Office \\
\hline Roof finish material: White coat & Lighting: $10.76 \mathrm{~W} / \mathrm{m}^{2}$ \\
\hline
\end{tabular}


Figure 3. Base case floor plan

Figure 4. Base case West Elevation
Energy Reduction, Daylight and View Quality Assessment of a Passive Dynamic Facade in Hot Arid Climate

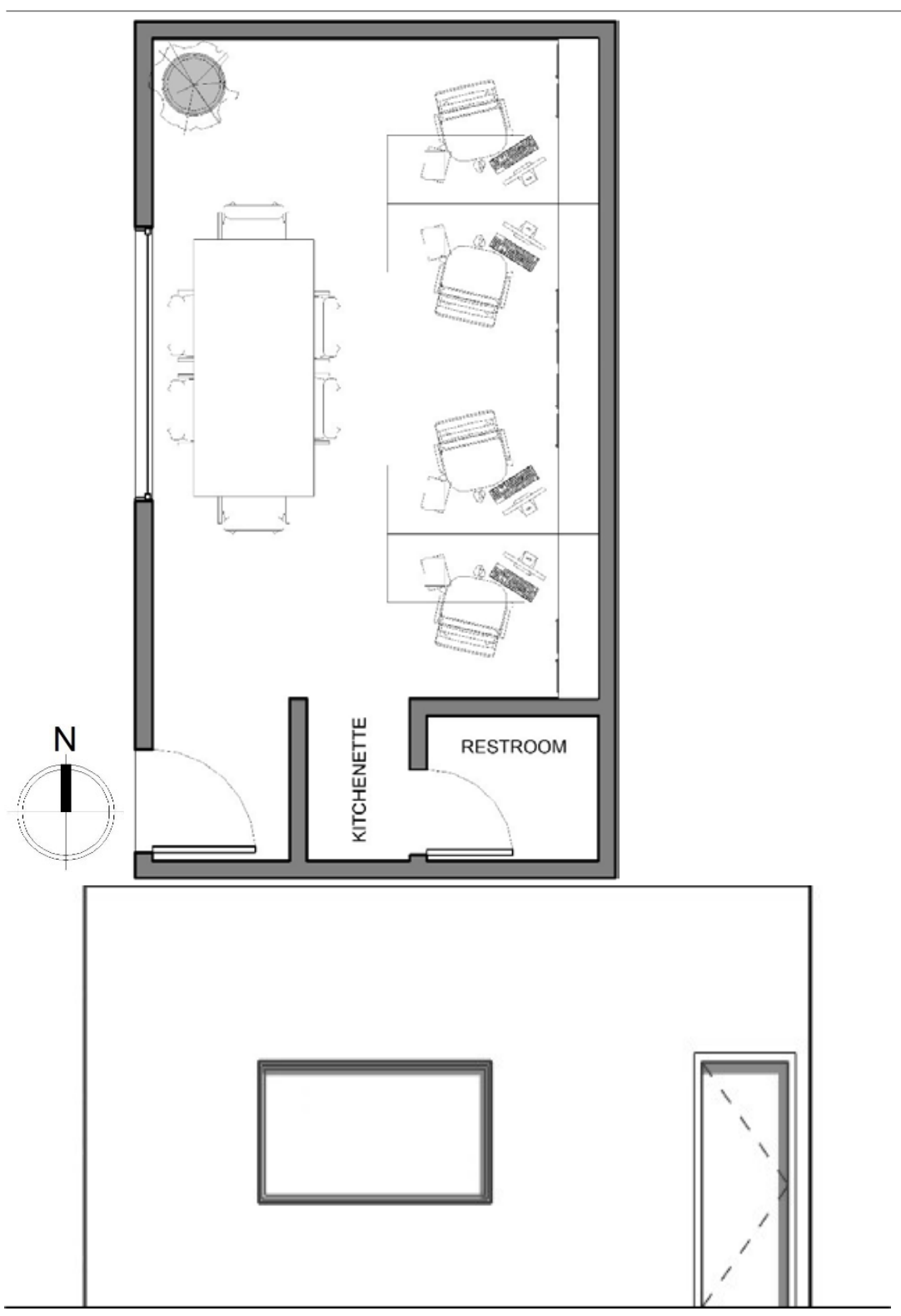

Fixed Shading Design: In hot climates, the most effective way to reduce the solar load on fenestration is to intercept direct radiation from the sun before it reaches the glass. Properly designed fenestration can significantly reduce the heating load during the winter months by admitting solar radiation. Just as significant, however, is protection from excessive solar radiation in the summer to reduce the cooling load. Fully shaded windows from the outside have a solar heat gain reduction of as much as $80 \%$ [12].

Fenestration can be shaded by overhangs (extension of the eve) or by vertical and horizontal architectural projections. The ability of horizontal panels or vertical louvers to intercept the direct component of solar radiation depends on their geometry and profile, or shadow-line angle. The profile (shadow-line) angle is defined as the angular difference between a horizontal plane and a plane tilted about a 
horizontal axis in the plane of the fenestration until it includes the sun (Figure 5.) [12].

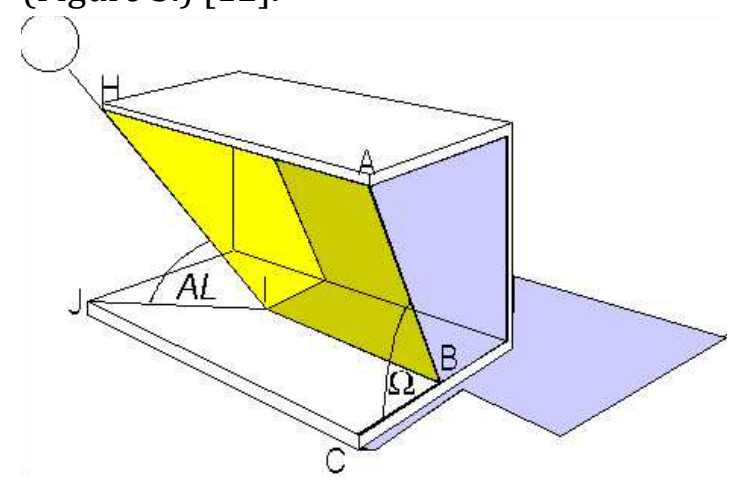

The profile angle $\Omega$ can be calculated by equation (1) [12]:

Tan $\Omega=$ TanAL / Cos(Solar AZ - Window AZ)

The window azimuth is $0^{\circ}$ if facing south, $90^{\circ}$ (or $-270^{\circ}$ ) if facing west, $180^{\circ}$ if facing north, and $-90^{\circ}$ (or $270^{\circ}$ ) if facing east (Figure 6.) [12].
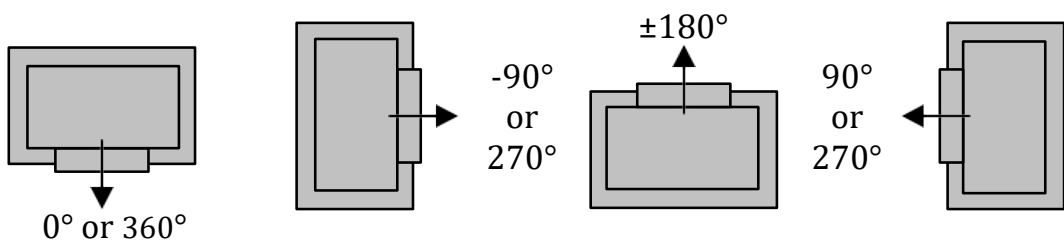

A shading device that works on a façade at a specific time will not necessarily be effective during other times of the day due to the diurnal factor. It is also true that shading devices designed for a specific season may not be effective for another season due to the seasonal factor. At low sun angles, especially early morning and late afternoon, horizontal overhangs cannot efficiently shade windows. Therefore, it is recommended that a continuous overhang be utilized to shade windows throughout the day in the summer.

Proposed Fixed Shading Devices: The proposed shading device protects the window from April 21 through the end of August, which is considered the summer season. On April 21 at $3.00 \mathrm{pm}$, Phoenix has an altitude angle of $49.06^{\circ}$ and an azimuth angle of $67.36^{\circ}$. To design efficient shading devices, the profile angle (shadow-line) must be calculated through equation (1).

The west profile angle is $\operatorname{Tan} \Omega=\operatorname{Tan} 49.06^{\circ} / \operatorname{Cos}\left(67.36^{\circ}-90^{\circ}\right)=51.3^{\circ}$ The south profile angle is $\operatorname{Tan} \Omega=\operatorname{Tan} 49.06^{\circ} / \operatorname{Cos}\left(67.36^{\circ}-0^{\circ}\right)=71.73^{\circ}$

To ensure an acceptable depth for the shading devices, the window as divided into four segments, each measuring one foot in height and the length of the window. Figure 7. shows a graphical method of designing shading devices. In this case, the shading dimensions are determined by drawing a perpendicular line from the bottom of the window to the bottom of the segment. The line is then rotated by the west profile angle to create the exact shading depth. In this case, the depth was rounded up from $93 / 16$ in to $1 \mathrm{ft}$ for simplification and to create a shade that will protect the window until 3:30 pm.
Figure 5. Profile or shadow-line angle $\Omega$ (by Prof. Nader Chalfoun)

Figure 6. Window azimuth (by Prof. Nader Chalfoun) 
Figure 7. Graphical method of calculating the depth of shading structure

Figure 8. Graphical method of calculating the length of continuous overhang

Figure 9. Interior space on December 21 at 3:00 pm

Figure 10. Interior space on April 21 at 3:00 pm
Energy Reduction, Daylight and View Quality Assessment of a Passive Dynamic Facade in Hot Arid Climate

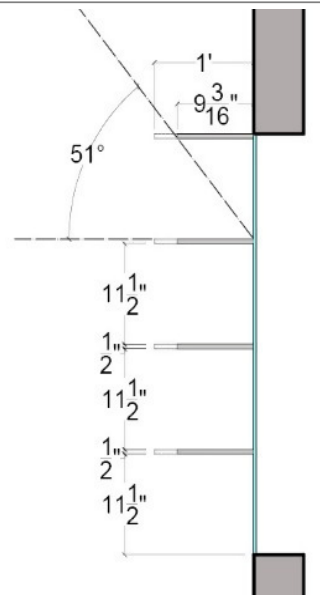

Figure 8. demonstrates the method of calculating the length of the continuous overhang. This is done by drawing a line from the bottom right of the segment and then rotating it by the south profile angle. To create a continuous overhang that is effective based on the diurnal factor, the overhang is extended until it meets the rotated line to create a 4-in overhang extension.
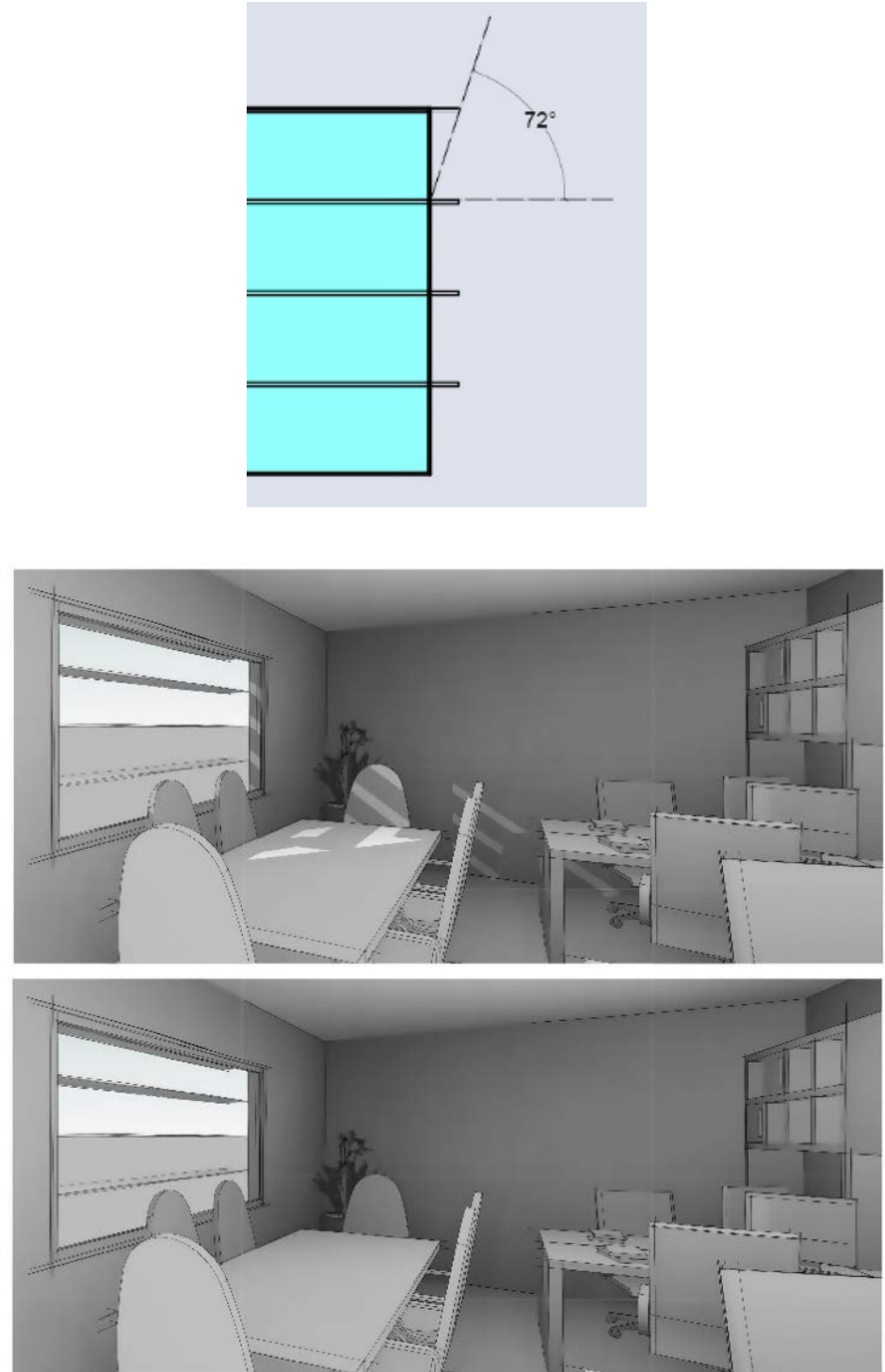
Proposed Passive Dynamic Shading devices (PDSD) Design: As explained in Section 4.3, the design of fixed shading is important when considering a shading system for a hot climate. The fixed shading must be designed for specific seasons and times of the day. Consequently, fixed shading is present on times and days not included in the shading design process, when it is not needed. The presence of fixed shading when it is not needed compromises daylight and energy consumption through increasing demand for electrical lighting. It also increases the heating load since the fixed shading partially blocks direct solar radiation in the winter. In addition, it obstructs views of the outdoors that enhance mental and physical health [13].

The PDSD is an innovation system that enhances energy consumption, daylight, and view quality through passive dynamic movement that allows the shading system to be used only when it is needed, mostly in the summer. The passive dynamic movement occurs through thermal expansion in the actuators. A PDSD increases the amount of useful daylight since it is not visible on winter mornings and most summer mornings, reducing energy demand for electrical lighting. This improves the cooling and heating load since the PDSD blocks the direct radiation in the summer, which increases cooling energy demand, and allows the winter sun, which reduces heating energy demand, to penetrate into the building. The view is optimized through timing of the appearance of the shading system, as it is in use only when it is needed for essential purposes, reducing the amount of time it obstructs the view.

The proposed PDSD follows efficient fixed shading design recommendations to enable a fair assessment of the impacts of dynamic shading compared to fixed shading. One of the main goals is for PDSDs to be feasible for all users. They are different from algorithmic dynamic facades, which rely on many sensors and a complicated operating system, and are cost-effective in terms of initial costs, maintenance, and operation. To ensure the system's simplicity and effectiveness, I worked within the restrictions of a typical configuration of an automatic window opener for greenhouses (Figures 11. and 12.) since this assembly is provided by many companies.
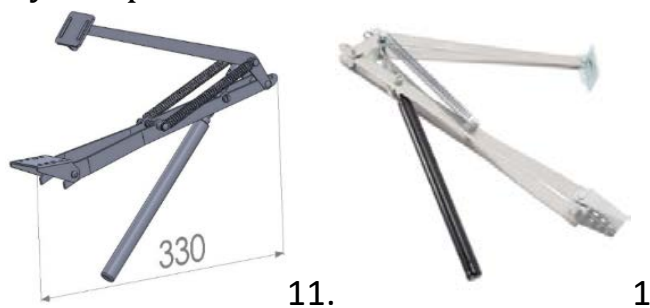

12.

The strictest limitation of the automatic window opener is the opening angle, which, since it relies on linear deployment, is difficult to extend past $90^{\circ}$. The assemblies generally have an opening temperature around $25^{\circ} \mathrm{C}$, or $77^{\circ} \mathrm{F}$, to optimize greenhouse temperatures. For this study, however, I assume a different opening temperature.
Figure 11. Univent Automatic Vent Opener (by J. Orbesen teknik ApS)

Figure 12. Automatic Vent Opener (by ACF Greenhouses,2019) 
Figure 13. Thermal actuator assembly (ThermOmegaTech, Inc., 2019)

Figure 14. Cross sections of the PDSD in all positions

Figure 15. Elevation of PDSD
Energy Reduction, Daylight and View Quality Assessment of a Passive Dynamic Facade in Hot Arid Climate

The automatic window opener is a thermal actuator which is also called thermal wax element, wax element, and thermostatic element. The thermal actuator assembly contains several components, as shown in Figure 13. No electrical energy is required to perform the actuation since the actuator converts heat energy into mechanical motion. The heat energy, represented by temperature, is calibrated to work at an activation setpoint to the engineered fluid (wax) located inside the actuator.

\begin{tabular}{|c|c|c|c|}
\hline \multicolumn{2}{|c|}{ DIAPHRAGM TYPE ACTUATOR } & \multicolumn{2}{|c|}{ SLIDING SEAL ACTUATOR } \\
\hline & 1 - Piston & & 1 - Piston \\
\hline-2 & 2- Guide & & 2- Guide \\
\hline 3 & 3- Anti-Chafing Disc & (3) & 3 - Seal \\
\hline (4) & 4- Plug & & 4 - Actuator Body \\
\hline & 5 - Diaphragm & & 5 - Thermoloid ${ }^{\oplus}$ Material \\
\hline (7) 6 & 6 - Actuator Cup & (5)- & \\
\hline Anst & 7 - Thermoloid ${ }^{\oplus}$ Material & & \\
\hline
\end{tabular}

According to the fixed shading design, the overhang must have a depth of $1 \mathrm{ft}$, but dynamic shading requires clearance between the shading device and the window. I used two rules of thumb for the PDSD design. First, the clearance is equal to the depth. Second, the system needs a fixed cavity with a depth twice that of the shading device (Figure 14.). The system must be connected so the folding mechanism can work. Therefore, I designed the vertical surfaces as hollow surfaces that act as a void to allow the occupants to have a view to the outside and allow diffuse light to penetrate to the interior (Figure 15.).

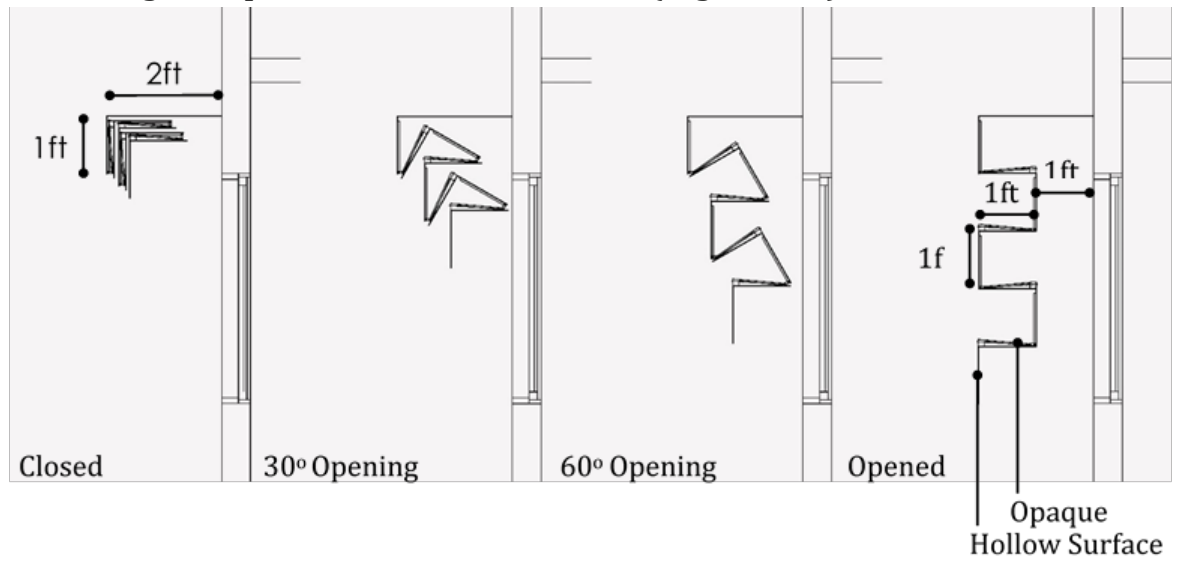


PDSD Operation Setup: After analyzing Phoenix's EnergyPlus weather data through the Archsim plug-in, I found the most frequent daytime dry-bulb temperature in the summer to be $35^{\circ} \mathrm{C}\left(95^{\circ} \mathrm{F}\right)$, which was determined by examining the temperature of the total 8,670 hours of a year (Figure 16.). Thus, $35^{\circ} \mathrm{C}\left(95^{\circ} \mathrm{F}\right)$ is the opening temperature for the PDSD. It is clear from Figure 16. that the device is in use for some hours off outside of the intended time of operation. However, the intended time of operation is $90 \%$ covered. Figure 17. demonstrates the temperature setup of the movement mechanism and shows efficient shading on June 21 at 3:00 pm.

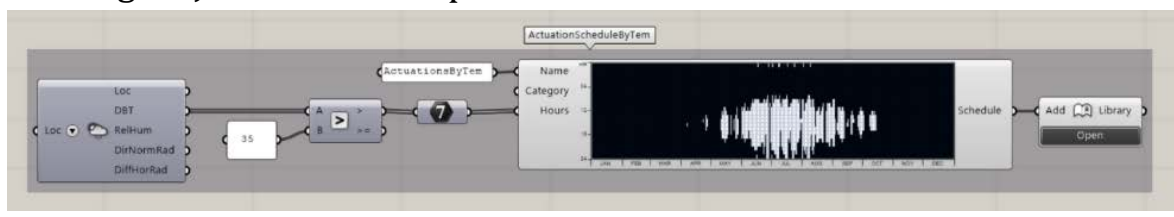

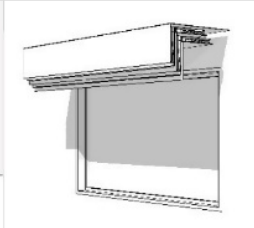

$\mathrm{DBT}<35^{\circ} \mathrm{C}-95^{\circ} \mathrm{F}$

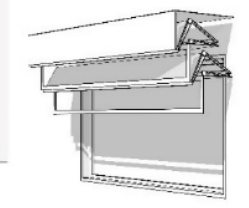
(

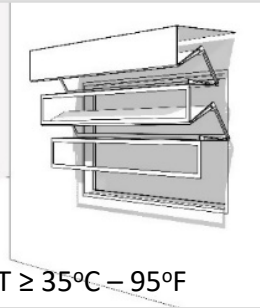

DBT $\geq 35^{\circ} \mathrm{C}-95^{\circ} \mathrm{F}$

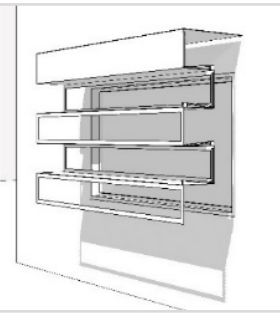

PDSD Schedule: The PDSD operation schedule, generated by the Archsim plug-in, provides $78 \%$ unshaded conditions when the system is closed, and $22 \%$ shaded conditions when the shading device is needed (Figure 18.).

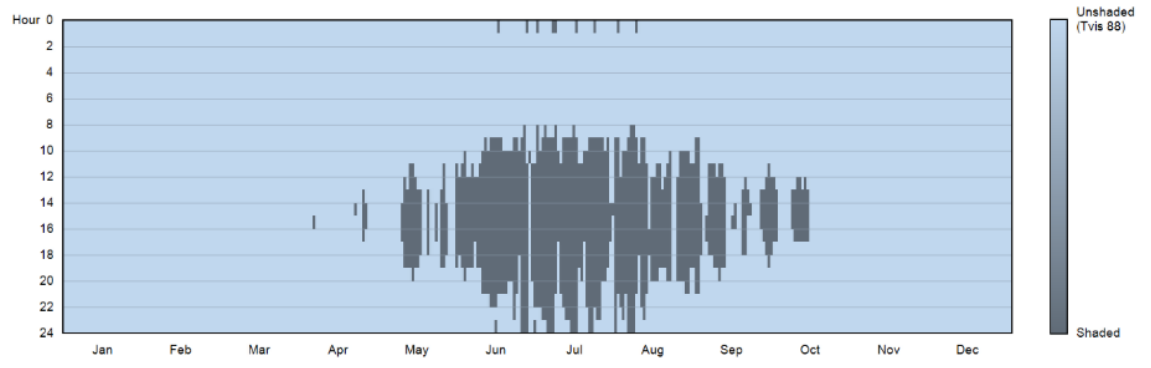

\section{TESTING AND RESULTS}

Figure 19. shows the workflow of the energy and daylight simulations completed with DIVA for Grasshopper.
Figure 16. Actuation setup

Figure 17. The relationship between dynamic movement and temperature

Figure 18. PDSD operation schedule 


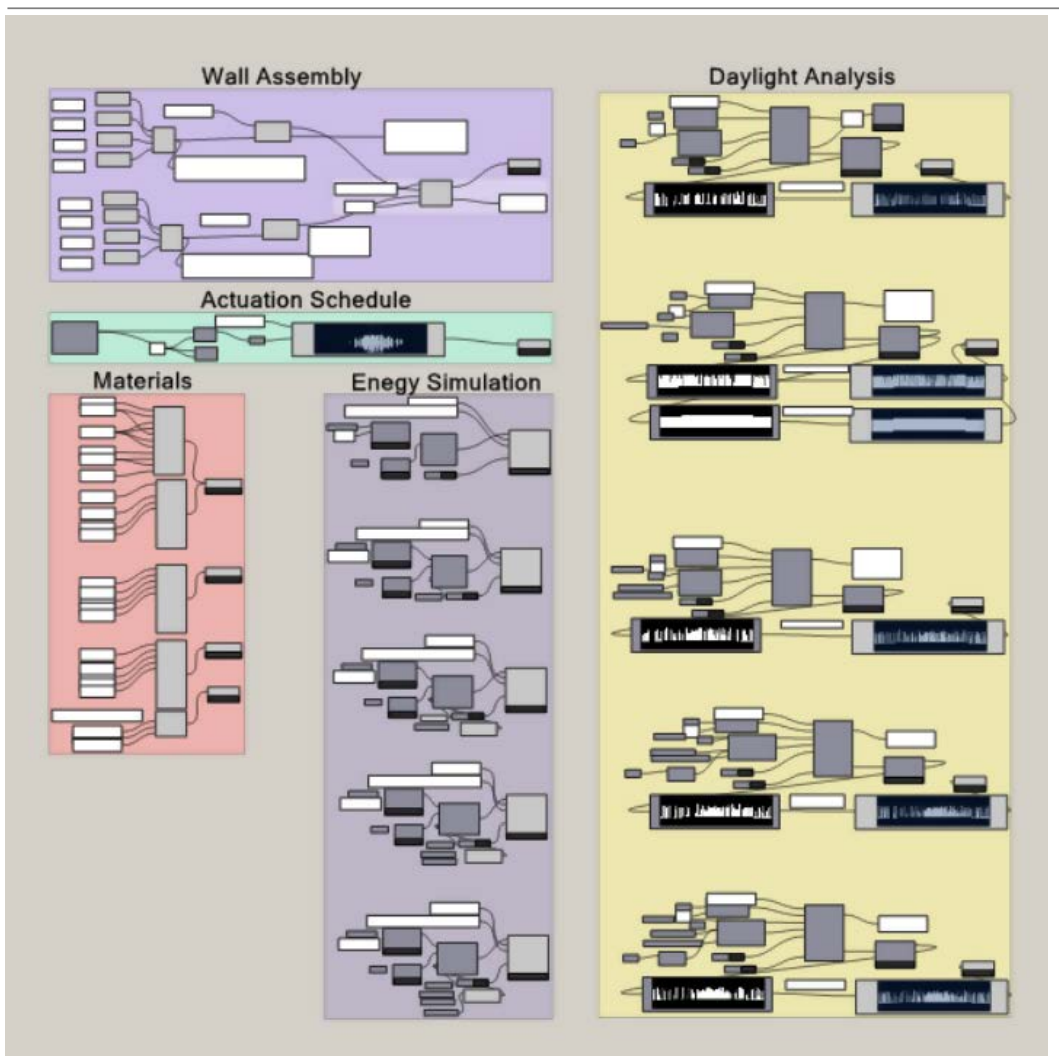

Daylight Analysis: In the field of daylight analysis, there several ways to evaluate daylight quality and amount. Each serves a specific purpose and provides different information for assessing the usefulness and strength of daylight in the design of architecture. In this study, I evaluated daylight quality in the Radiance platform using four methods since they provide a comprehensive understanding of daylight quality and characteristics.

1.Daylight autonomy (DA)

2.Continuous daylight autonomy (CDA)

3.Useful daylight Illuminance (UDI)

4.Daylight availability (DAv)

Energy Simulation: Energy simulation is used to that replicate the realtime performance of a building. The analysis illustrates how the thermodynamics in a selected building works in a specific climate region. Understanding the thermodynamics helps designers comprehend the strengths and weakness of a building envelope, enabling them to enhance energy performance. In this research, I assessed energy performance through four types of energy simulation, which provide the require information to understand the thermodynamic behavior, using the EnergyPlus platform:

1.Total ideal cooling energy

2.Total ideal heating energy

3.Total lighting electric energy

4.Total heat gain energy through windows

View Quality Analysis: In LEED v4, view quality credits are achieved with $75 \%$ direct sight to the outdoors through the glazing of all 
regularly occupied floor areas. The view must provide clear access to the exterior and be unobstructed by frits, fibers, patterned glazing, or added tints that distort the color balance. View obstruction plays a significant role in view quality. In this research, I consider shading devices obstructions to the view since they create a potentially dense pattern on windows. Thus, the percentage of time of obstruction and the obstruction density are calculated.

\section{Base Case}

As mentioned earlier, the base case has no shading device system. Figure 20. shows the west elevation of the base case.

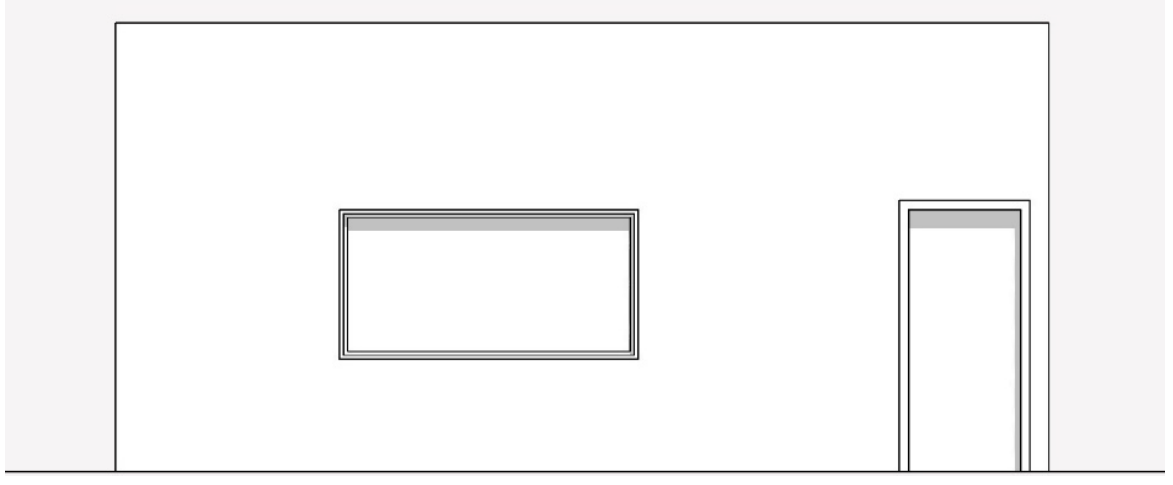

Figure 20. West façade of base case

Daylight Analysis: Figure 21. illustrates the daylight analysis with four study types. The DA and cDA studies demonstrate the amount of daylight over the course of the year and show that the window provides an amount of daylight that meets the 300 Lux criteria for the space. However, the DAv analysis in Figure 21. shows high values for the floor area, indicated in purple, that exceed 10 times the illumination threshold of 3,000 Lux at least 5\% of the time, which is mostly due to direct solar radiation. Exposing the interior space to the direct solar radiation potentially creates glare and visual discomfort and can cause the space to overheat in the summer. The UDI study shows that the useful daylight may be inadequate for some specific tasks, but it is sufficient for normal work. 
Energy Reduction, Daylight and View Quality Assessment of a Passive Dynamic Facade in Hot Arid Climate
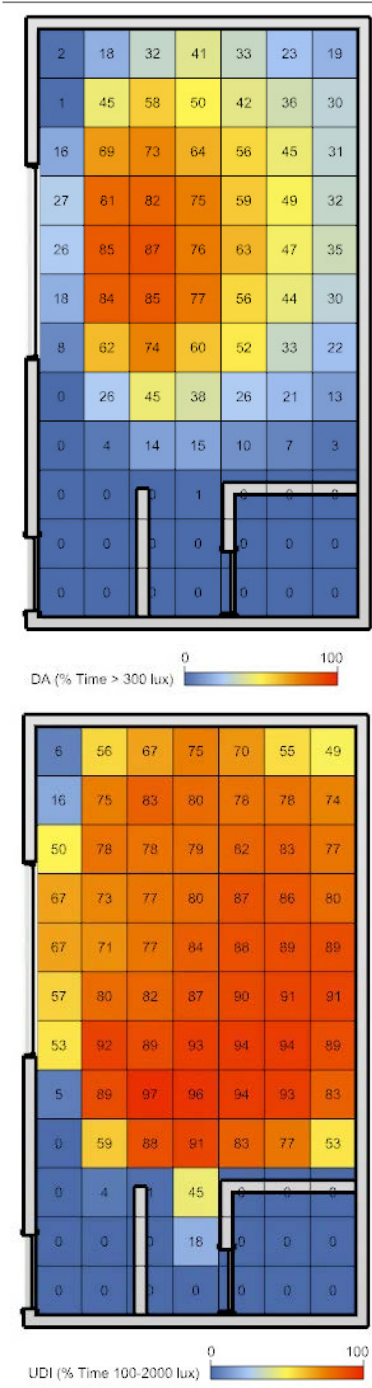
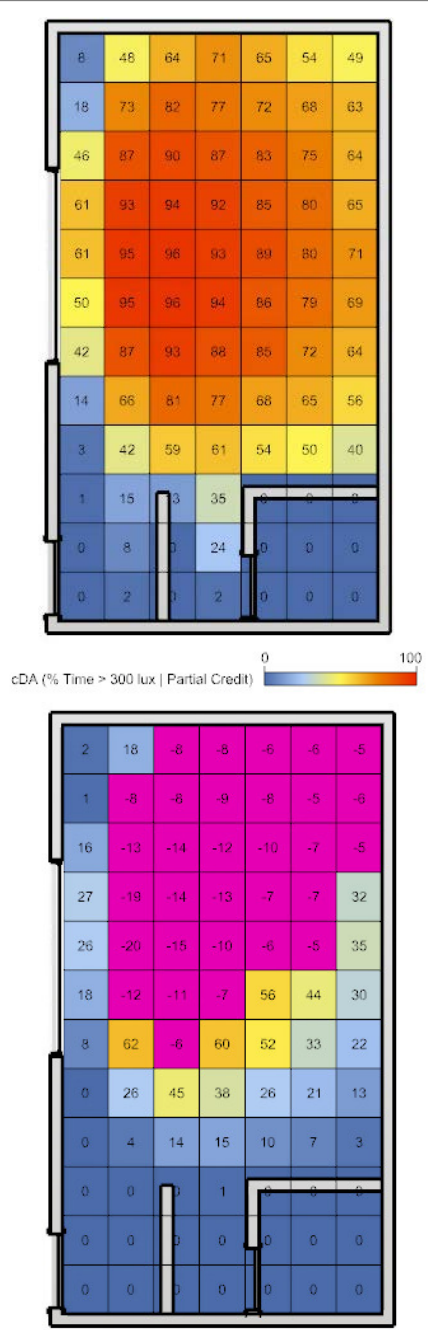

Dayight Availability $(\%$ Time $>300 \mathrm{lux})$

Energy Simulation: Figure 22. presents the energy simulation for the base case. In this case, cooling energy is a critical factor for energy savings since, as shown in this graph, it accounts for almost 10 times the energy required for heating and lights. The peak of cooling energy demand is in the summer. Demand is increased through heat gain from the window and transmitted solar radiation energy because the window is not protected from solar radiation, exposing the interior to direct heat. Heating energy is not critical in the hot, dry climate in which the base case is located. As shown in the graph, heating energy demand is generally low throughout the year and nonexistent during the summer. Lighting energy demand is quite low in this study since the window provides an adequate amount of natural light, which helps avoid the excessive use of artificial lighting. 


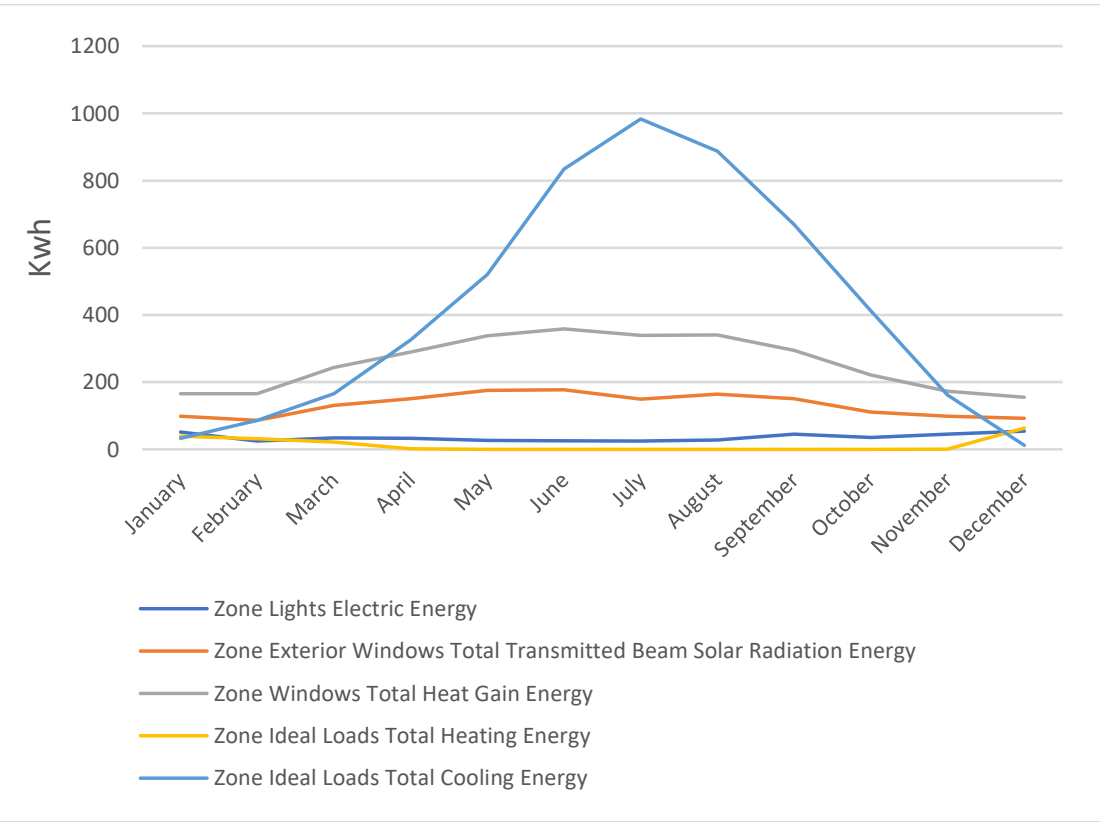

View Quality: The base case has a wonderful view of the outdoors that is unobstructed throughout the year (Figure 23.).

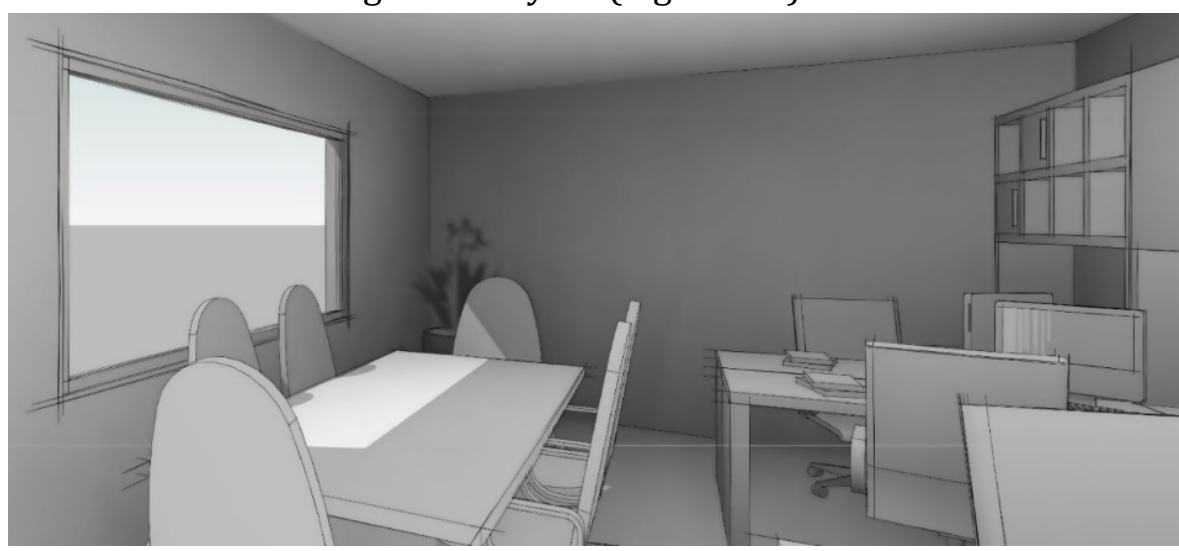

\section{Fixed Shading Case}

The fixed shading case has an efficient fixed shading device that protects the window from direct solar radiation during the entire summer. Figure 24. shows the west elevation of the fixed shading case.

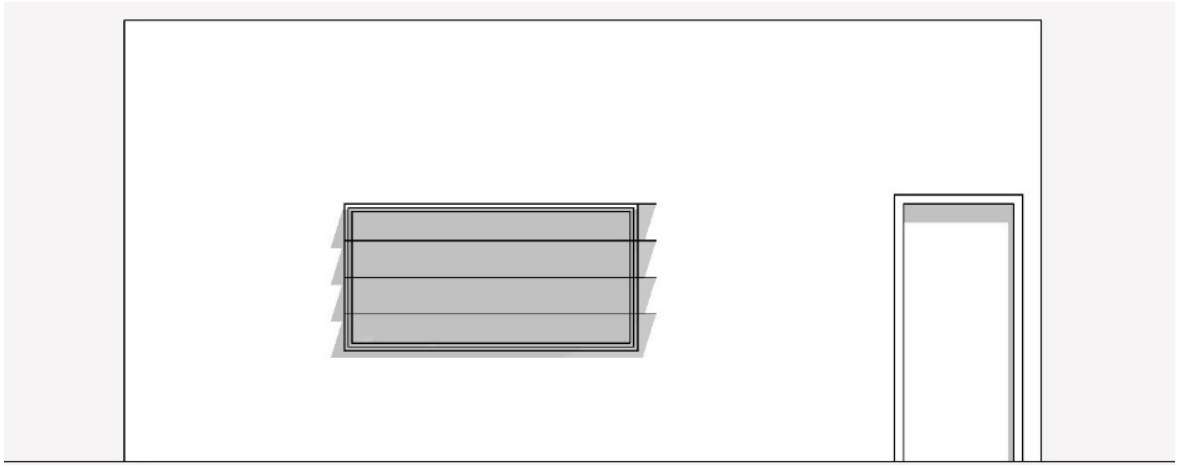

Daylight Analysis: Figure 25. shows the daylight analysis for the fixed shading case. The general trend, as illustrated by the results of the DA
Figure 22. Base Case Energy Simulation

Figure 23. Base Case Energy Simulation

Figure 24. West façade of the fixed shading case 
Energy Reduction, Daylight and View Quality Assessment of a Passive Dynamic Facade in Hot Arid Climate

and cDA studies, is an inadequate amount of daylight, as the existing shading device reduces the amount of diffuse and direct natural light that can penetrate to the interior. While it is desirable to block direct radiation to improve energy consumption and visual comfort, as the DAv study shows, the reduction of diffuse daylight causes a decrease in the amount of useful illumination. The results of the UCI study, which has a relatively low threshold of 100 Lux, demonstrate this.
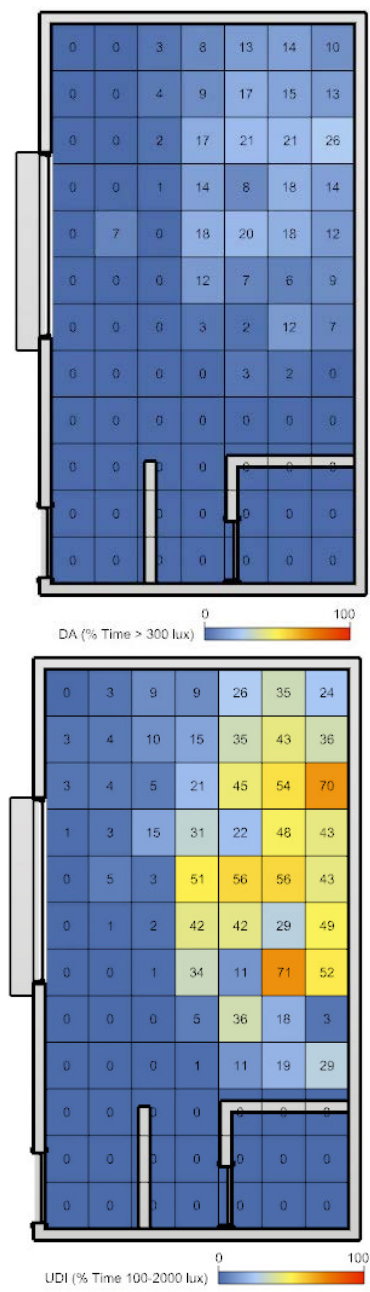
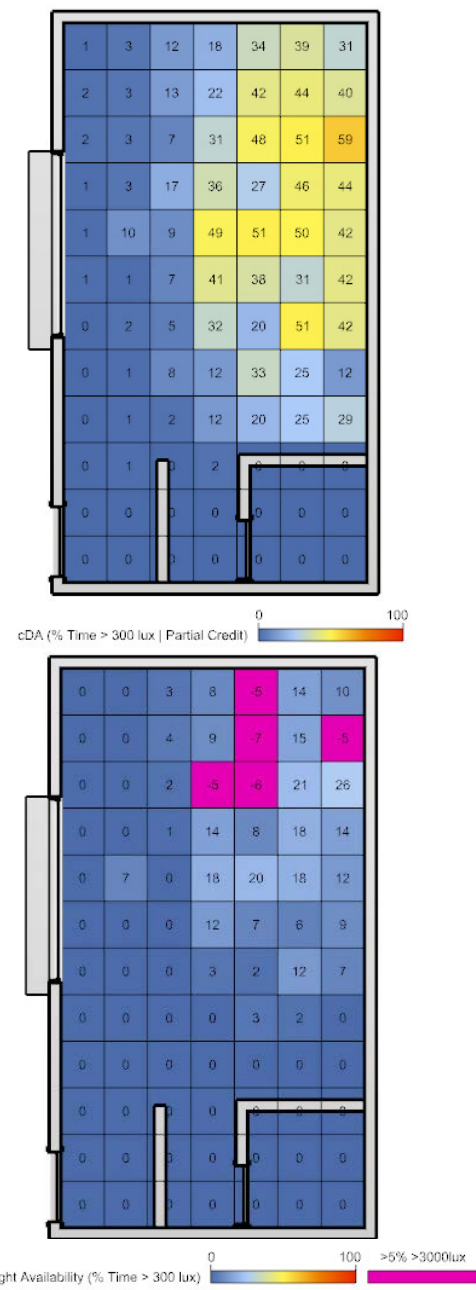

Figure 25. Fixed shading case daylight analysis
Energy Simulation: Figure 26. demonstrates the energy performance of the fixed shading case. As shown in the graph, demand for cooling energy is high compared to other types of energy demand. The shading device decreases cooling demand by blocking the summer solar radiation transmitted to the space and reducing heat gain through the windows. However, the low quality of daylight for the fixed shading case, as discussed in the previous section, affects demand for lighting energy in the energy simulation, as the use of artificial light is increased. The shading device allows winter solar radiation to penetrate the interior, which helps decrease heating energy demand. The graph shows no need for heating energy in the summer and low demand for heating in the winter. 


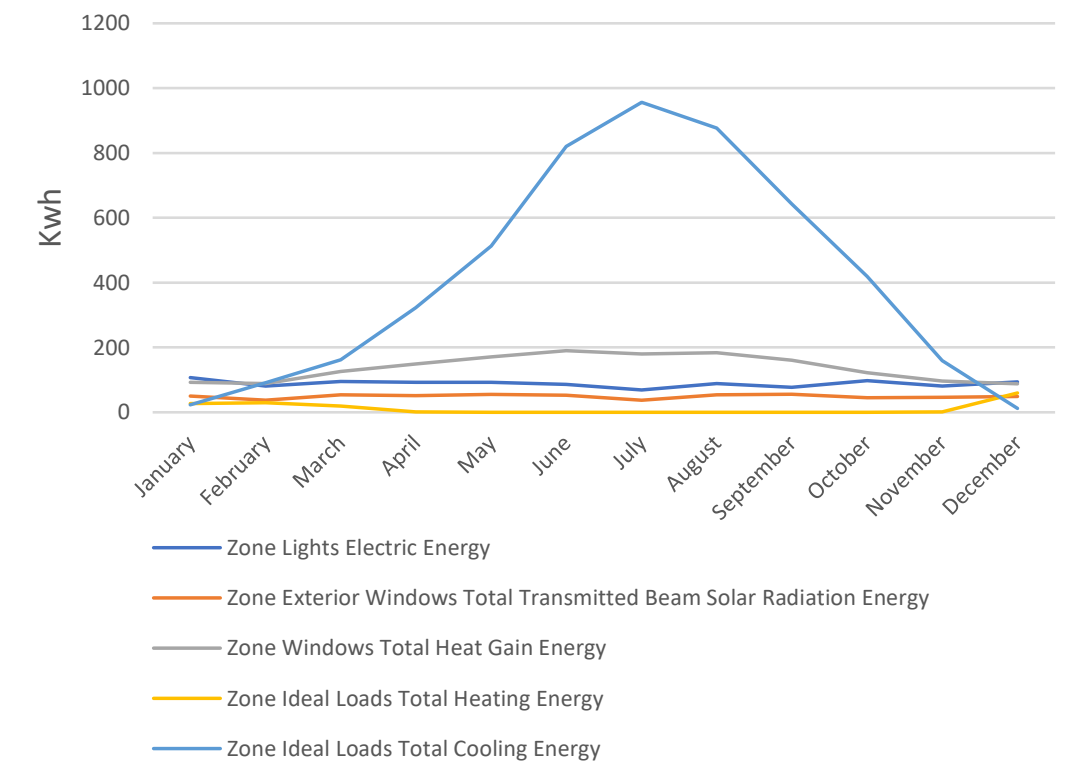

View Quality: The fixed shading case has a view of the outdoors that is partially obstructed during the course of the year by the shading device (Figure 27).

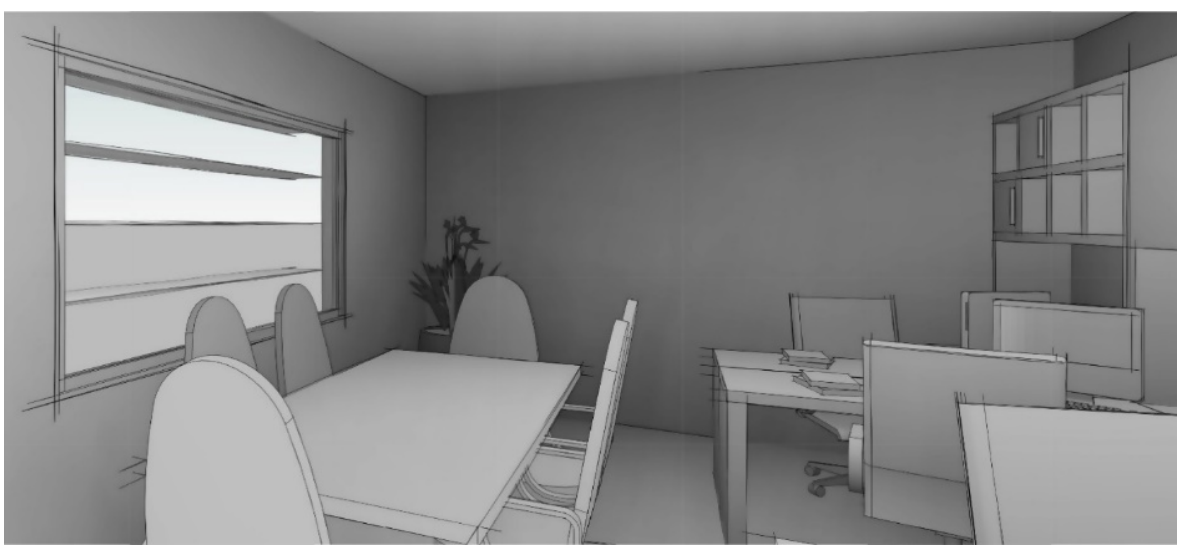

\section{PDSD System}

A PDSD is a dynamic shading system that passively actuates corresponding to the outdoor temperature, as extensively discussed earlier. Figure 28. shows the west elevation of the PDSD case.

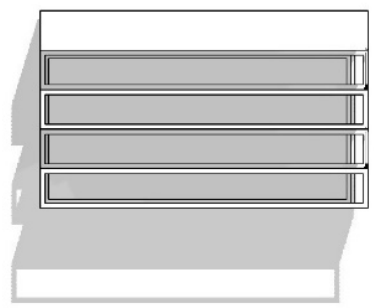

Figure 26. Fixed shading case energy simulation

Figure 27. Interior of the fixed shading case

Figure 28. West façade of the PDSD case 
Daylight Analysis: Figure 29. elaborates the daylight analysis for the PDSD case. The annual daylight that enters the space is shown by the DA and cDA studies, which indicate adequate daylight over the course of the year in the work area. The PDSD system is beneficial for daylight quality because its dynamic movement allows full penetration of natural light during most of the summer, when direct solar radiation does not interact with the window, and over the entire winter. The DAv study shows the over-lit area in purple, which has low daylight percentage throughout the year. According to the PDSD actuation schedule, there are times during the winter when the system is not operational and thus the over-lit area could cause visual discomfort during this time. However, this will reduce the heating load. The useful illumination in this case is efficient for most of the tasks throughout the year, as illustrated by the UDI analysis.
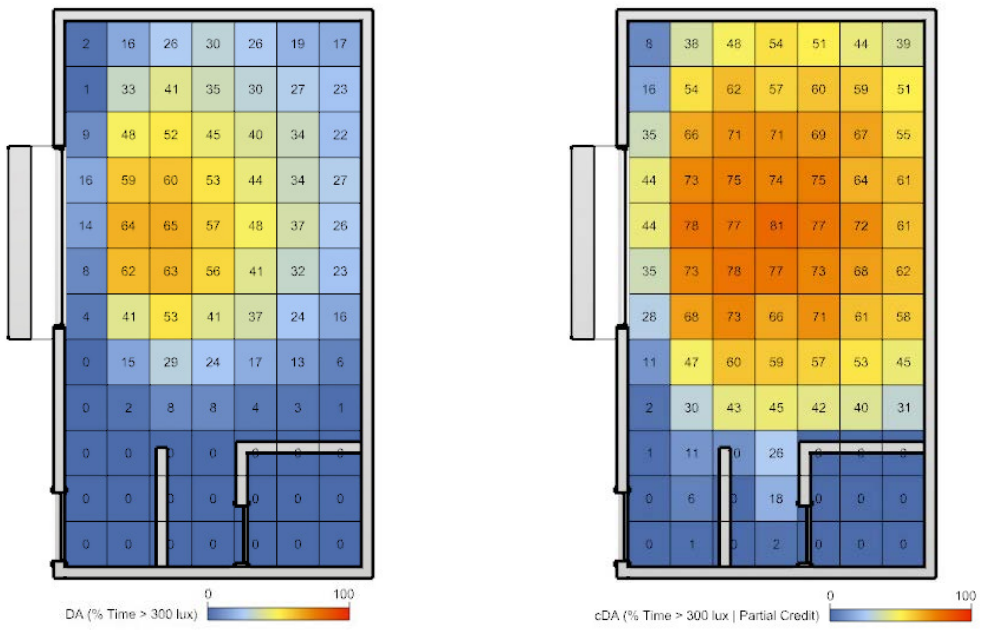

Figure 29. PDSD case daylight analysis
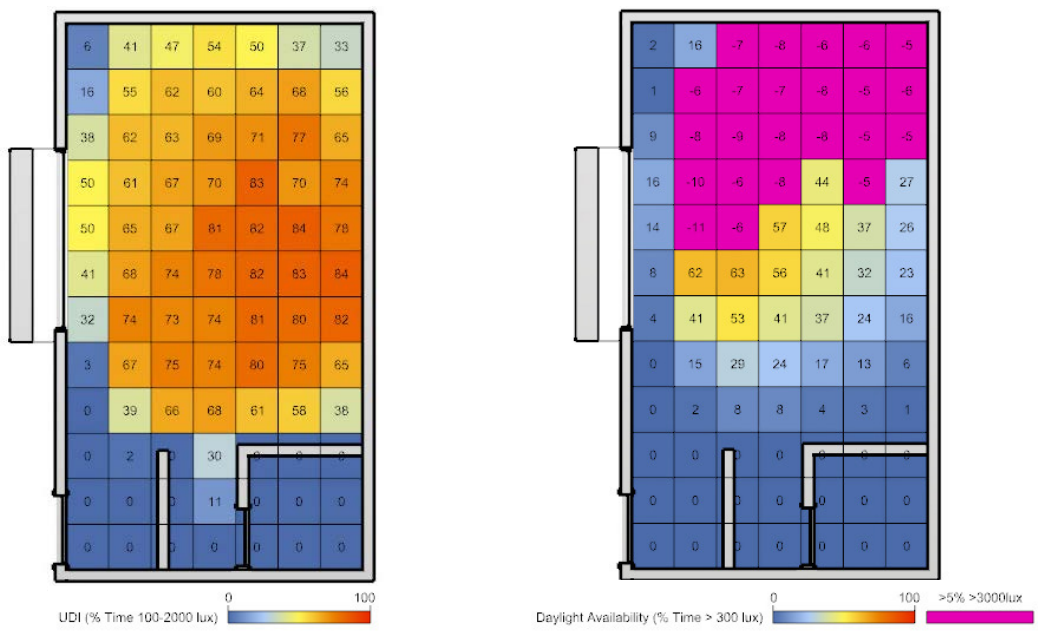

Energy Simulation: Figure 30. illustrates the energy performance of the PDSD case. It shows a cooling energy demand peak in July, as the result of the high energy demand in hot, dry climates. The PDSD improves cooling and heating performance through its dynamic movement since it blocks the direct solar radiation that is transmitted in the summer and allows it to penetrate the building in the winter. This results in a 
reduction of heat gain through the window in the summer and an increase in the winter. The daylight quality and amount of the PDSD case reflect positively on the consumption of lighting energy demand since the window provides a decent amount of natural light, decreasing the need to use artificial light. As Figure 30. shows, lighting energy demand is relatively low and steady, which means that the daylight amount generally remains constant throughout the year.

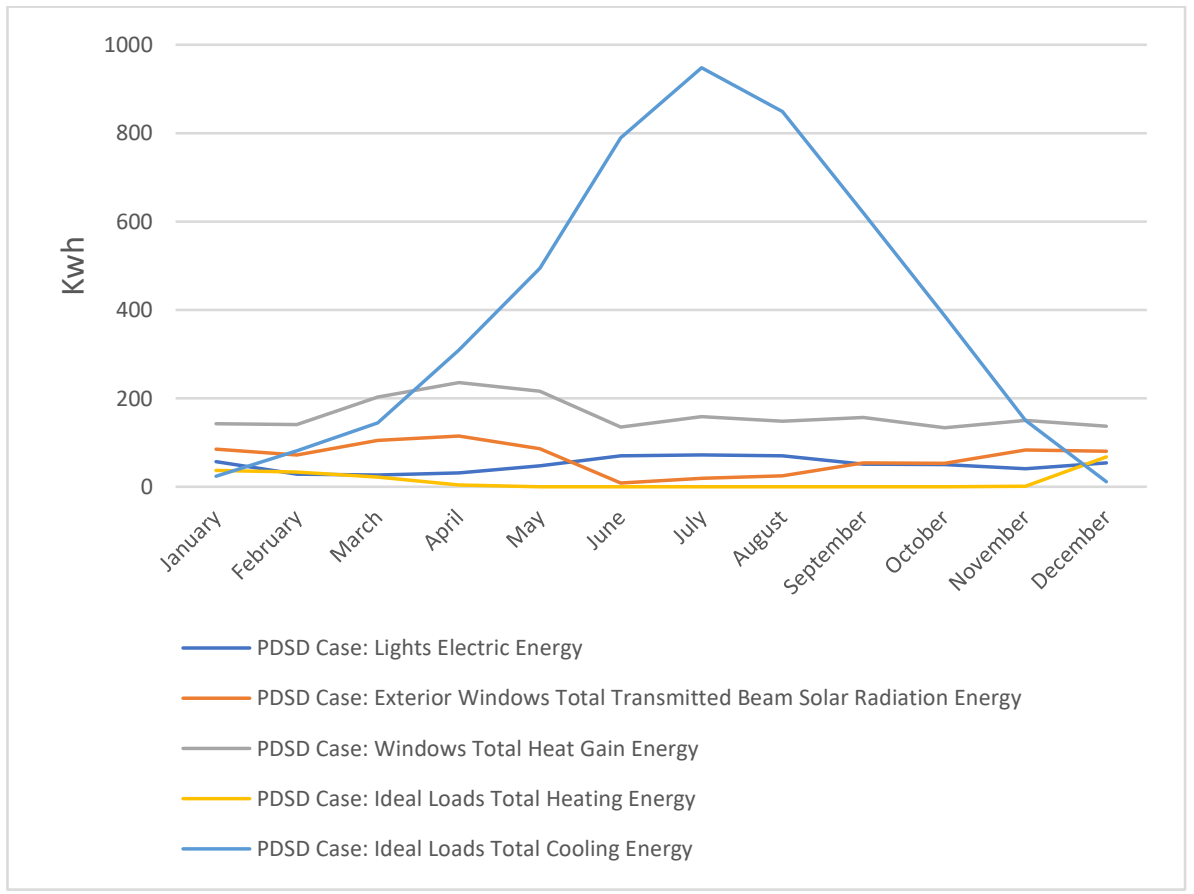

View Quality: The PDSD case has a window that provides a partially obstructed view $22 \%$ of the year. Mitigation of the time of obstruction is a result of the dynamic movement of the PDSD.

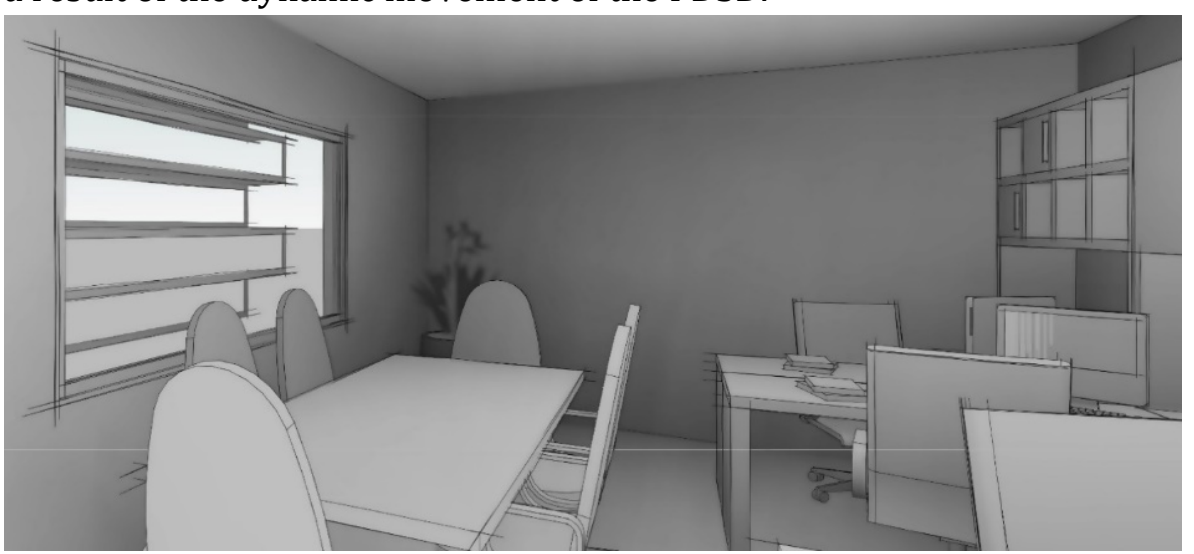

\section{Daylight comparison}

Daylight comparison namely DA, cDA, UDI, and DAv studies, was conducted for the base case, fixed shading case, and PDSD case. The aim of the comparison was to determine the most efficient case. As Figure 32. shows, the DA values for the base case were high and demonstrated adequate illumination compared to the fixed shading case. However, the PDSD case provided a decent amount of daylight and values relatively
Figure 30. PDSD case energy simulation

Figure 31. Interior of the PDSD case 
Figure 32. DA comparison between the three cases

Figure 33. cDA comparison between the three cases

Figure 34. DAv comparison between the three cases

Figure 35. UDI comparison between the three cases
Energy Reduction, Daylight and View Quality Assessment of a Passive Dynamic Facade in Hot Arid Climate

close to those of the base case. The fixed shading case did not provide sufficient daylight for occupants' tasks. The cDA values exhibited the same pattern as the DA values in Figure 33. as well as the UDI rates in Figure 34 . The over-lit area in the base case was $40.5 \%$ of the total area with a high time percentage, which affected energy performance, as discussed in the following section, especially in the middle of the room and close to the window, as shown in Figure 35. In contrast, the fixed shading case had over-lit area of $6 \%$ with a very low time percentage. The over-lit area of the PDSD case was $27.4 \%$ of the total area with a low time percentage as direct solar radiation only in the winter is considered.
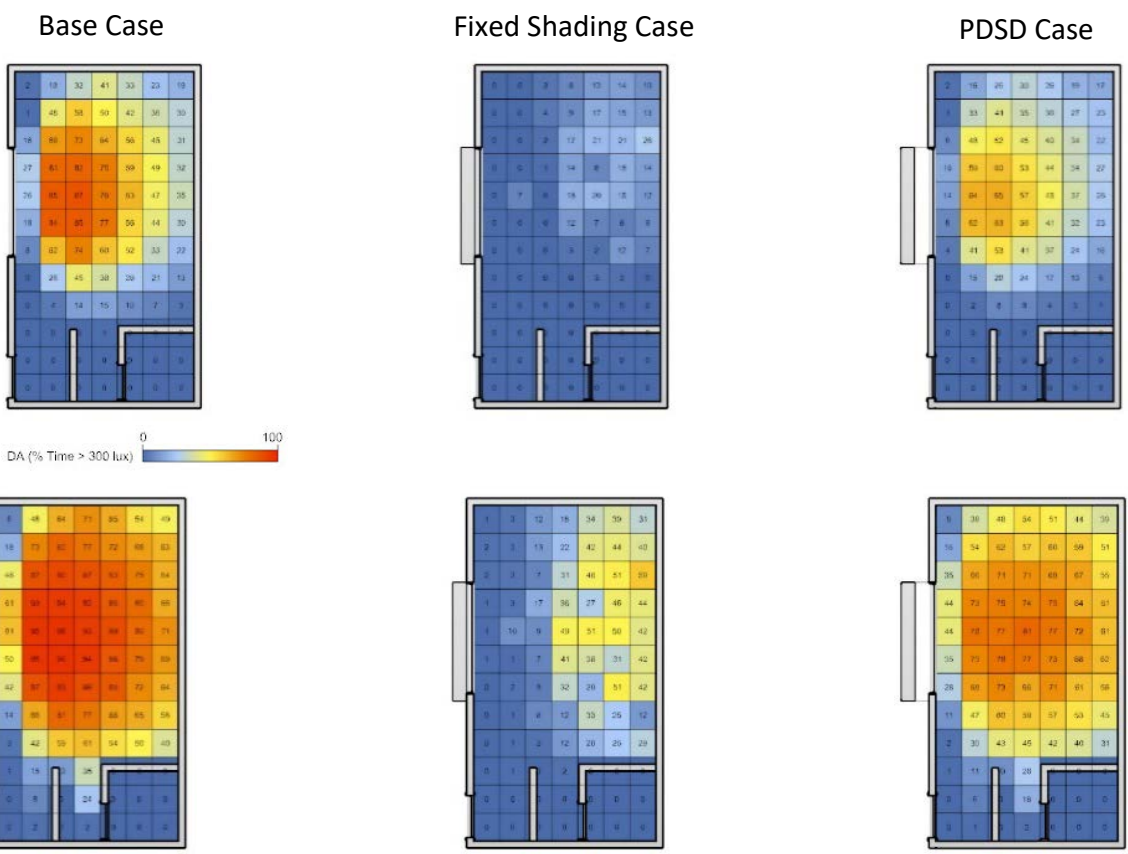
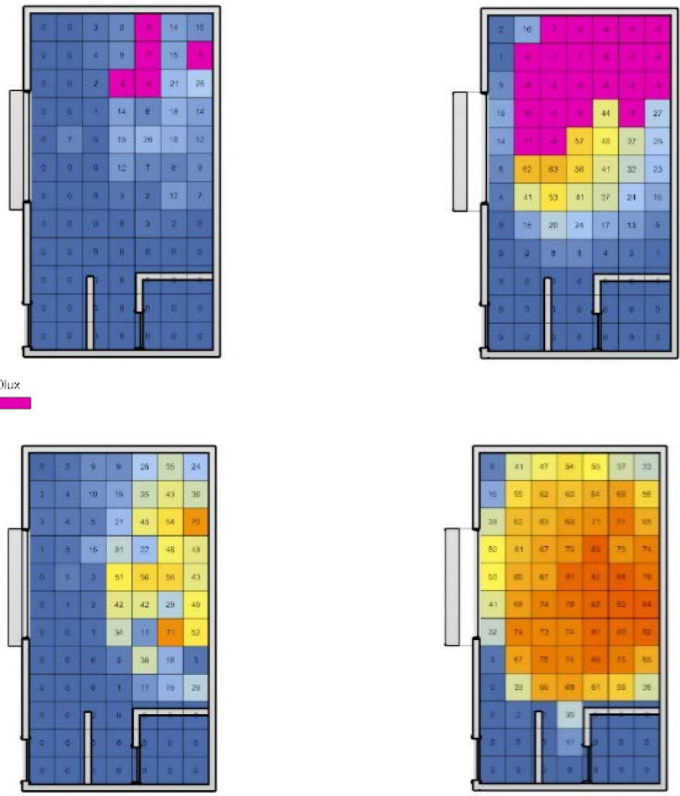


\section{Energy Simulation Comparison}

The energy simulation comparison compares the ideal load of cooling and heating energy and lighting energy for the base case, fixed shading case, and PDSD case. The purpose of this comparison is to find the most efficient of the three cases. Figure 36. shows the ideal cooling energy load, which is similar for all three cases in the winter since all of them allow direct radiation to penetrate the building. In the summer, however, there is more differentiation. Peak cooling energy demand is in July. The base case has the highest demand since the interior space is totally exposed to direct solar radiation. The fixed shading case has less demand than the base case, and the PDSD case has the lowest cooling demand since, unlike fixed shading, it reduces daylight, leading to more reliance on artificial lighting, which is a heat source.

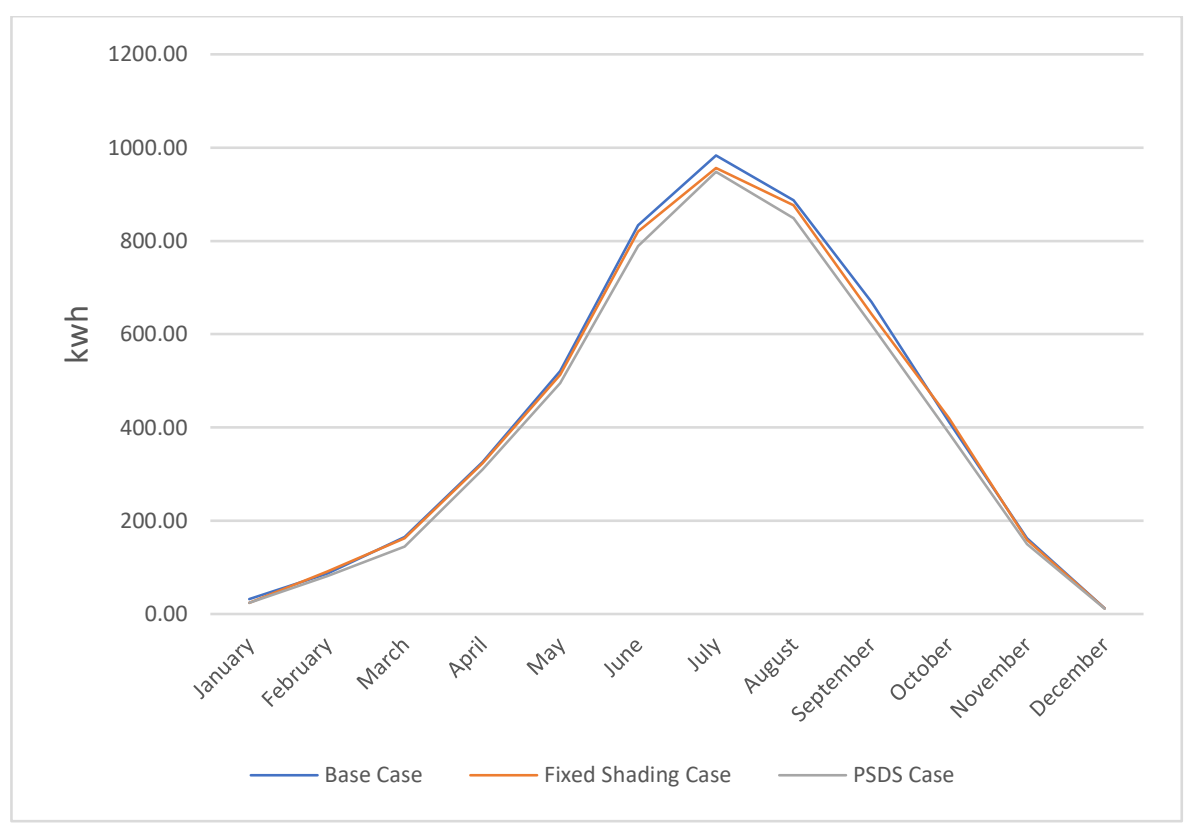

Figure 37. presents the ideal heating energy load. Heating demand of the three cases is relatively similar since they all allow solar radiation to heat the interior space in the winter. Figure 38. shows the lighting energy demand. The fixed shading case was the worst among the cases because the presence of shading devices all the time reduces the amount of daylight. The performance of the PDSD case is between that of the base case and the fixed shading case because it dynamically allows adequate daylight in the space.
Figure 36. Zone ideal total cooling energy load 
Figure 37. Zone ideal total heating energy load

Figure 38. Zone lighting energy demand
Energy Reduction, Daylight and View Quality Assessment of a Passive Dynamic Facade in Hot Arid Climate

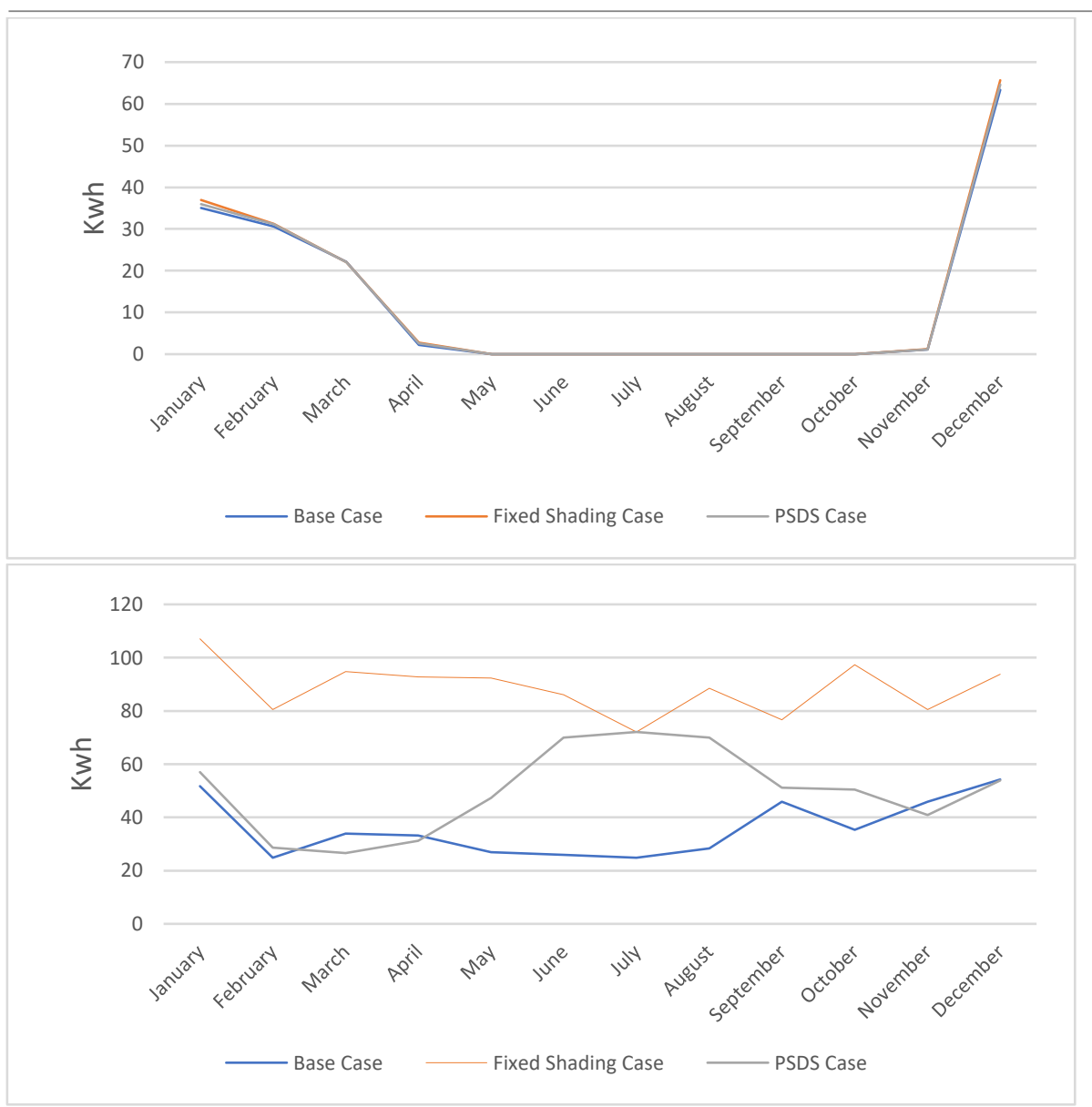

\section{View Quality Comparison}

The view analysis is based on a logical analysis. The base case has a clear view $100 \%$ of the time, the fixed shading case has a partially obstructed view $100 \%$ of the time, and the PDSD case has a partially obstructed view $22 \%$ of the time.

\section{Base Case}

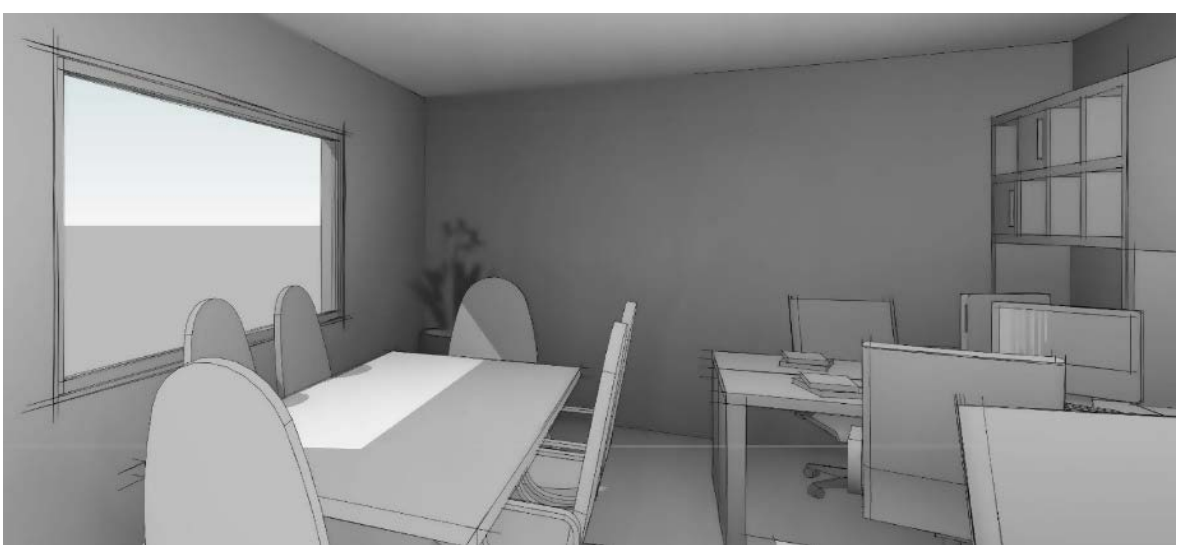




\section{Fixed Shading Case}

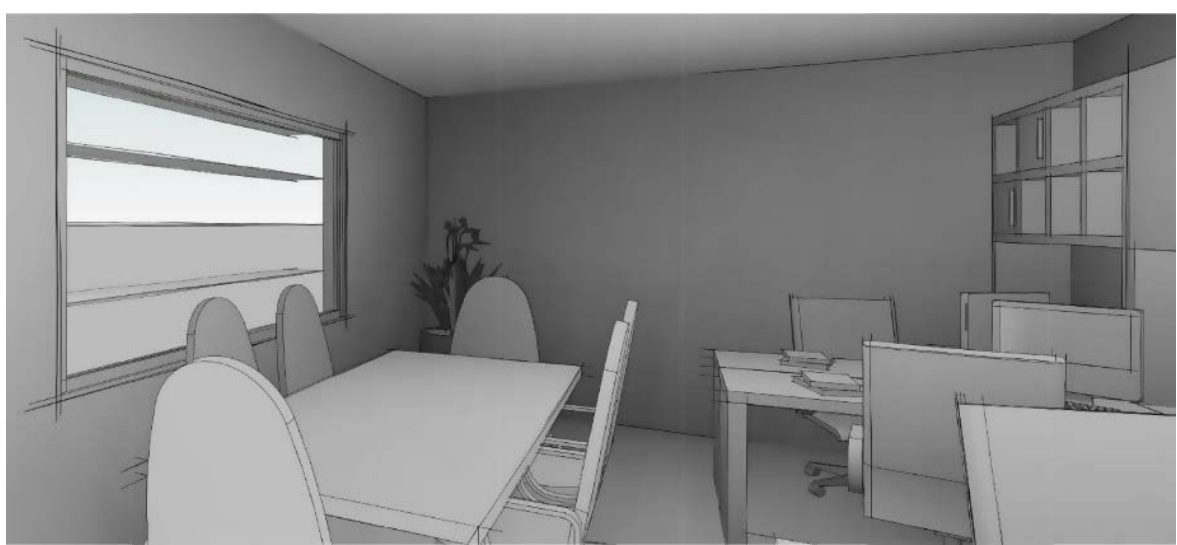

PDSD Case

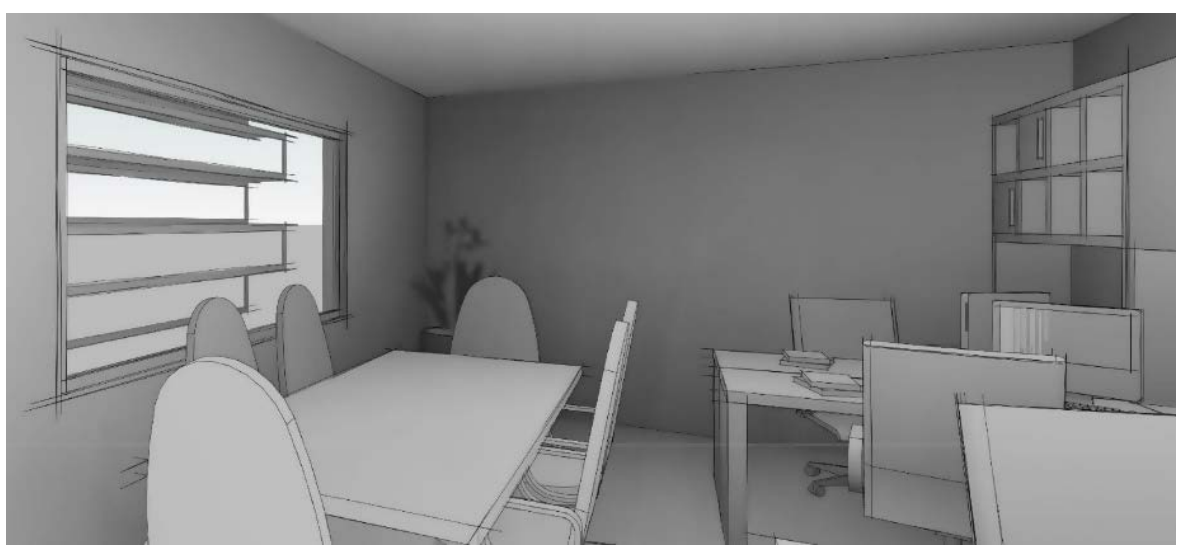

\section{Conclusive comparison}

Figure 40. illustrates in detail the quality of daylight and the amount of energy consumption in all cases. It shows energy saving and additional consumption comparing with base case. It describes the view quality with the time rate and obstruction conditions.

Table 3. Conclusive comparison of base case, fixed shading case, and PDSD case (by author)

\begin{tabular}{|c|c|c|c|}
\hline & Base Case & Fixed Shading & PDSD \\
\hline Cooling & $5090.91 \mathrm{Kwh}$ & $-1.8 \%$ & $-5.55 \%$ \\
\hline Heating & $158.58 \mathrm{Kwh}$ & $-7.6 \%$ & $282.51 \mathrm{Kwh}$ \\
Energy & & $12.06 \mathrm{Kwh}$ & $5.82 \mathrm{Kwh}$ \\
\hline Lighting & $431.04 \mathrm{Kwh}$ & $+146.43 \%$ & $+38.96 \%$ \\
Energy & & $631.18 \mathrm{Kwh}$ & $167.94 \mathrm{Kwh}$ \\
\hline Daylight & $26.2 \%$ & $0 \%$ & $13.1 \%$ \\
\hline
\end{tabular}

Figure 39. View quality comparison between base case, fixed shading case, and PDSD case 
Energy Reduction, Daylight and View Quality Assessment of a Passive Dynamic Facade in Hot Arid Climate

\begin{tabular}{|c|c|c|c|}
\hline Autonomy & & & \\
\hline Over-lit Area & $40.5 \%$ With & $6 \%$ with low & $27.4 \%$ with low time \\
of Total Area & high time Rate & time rate & rate \\
\hline View Quality & $100 \%$ of time & $100 \%$ of time & $22 \%$ of time partially \\
& unobstructed & partially & obstructed \\
& & obstructed & \\
\hline
\end{tabular}

\section{CONCLUSION}

Energy performance, daylight, and view quality generally contradict each other and thus it is unreasonable to optimize one factor over the other since this would compromise the values. The appropriate solution is to find the right balance between the objectives. In this research, I assessed the thermal performance, daylight, and view quality of three different cases in the same building. Two cases have a distinct type of shading system, and the remaining case has no shading system. The base case has a sufficient amount of daylight throughout the year, but because this includes direct sunlight in both the summer and winter, this can cause visual discomfort. Exposure to direct solar radiation causes a large amount of heat to transfer through the window in the summer, resulting in high cooling demand. However, the view was clear and unobstructed for the base case.

The fixed shading case was highly protected from direct solar radiation in the summer, resulting in low cooling energy consumption. Consumption could be lower, but the heat from artificial lighting contributed to cooling demand. Because the shading device reduced the amount of daylight, reliance on electric lighting was increased. The view was partially obstructed throughout the year.

The PDSD case offered the best balance among all the cases. It had the lowest cooling energy demand since it was mostly protected from direct solar radiation in the summer. Further, it had less need for electric lighting than the fixed shading case throughout the year and higher than the base case in summer. This case provided adequate daylight for office tasks throughout the year. While the amount of daylight was lower than the amount for the base case, it was high-quality daylight with only a $22 \%$ view obstruction over the year, unlike the base case, which did not receive abundant direct sunlight.

\section{ACKNOWLEDGMENTS}

This work would not have been possible without the department of architecture, Qassim University support and encouragement by providing me with a scholarship to do a graduate study at The University of Arizona. I am thankful for all who helped and supported 
me during my study at The University of Arizona, College of Architecture, Planning, and Landscape Architecture.

\section{CONFLICT OF INTEREST}

No conflict of interest was declared by the authors

\section{FINANCIAL DISCLOSURE}

The authors declared that this study has received no financial support.

\section{ETHICS COMMITTEE APPROVAL}

Ethics committee approval was not required for this article.

\section{LEGAL PUBLIC/PRIVATE PERMISSIONS}

In this research, the necessary permissions were obtained from the relevant participants (individuals, institutions, and organizations) during the survey and in-depth interviews.

\section{REFERENCES}

Marique, A. F., Dujardin, S., Teller, J., \& Reiter, S. (2013). Urban sprawl, commuting and travel energy consumption. Proceedings of the Institution of Civil Engineers-Energy, 166(1), 29-41.

GrIGorescu, I., MItrIcă, B., \& Mocanu, I. (2015). Assessing urban sprawlrelated housing dynamics in the Romanian Metropolitan Areas. Studia Obszarów Wiejskich, 38, 145-164.

Alam, M. M., Murad, M. W., Noman, A. H. M., \& Ozturk, I. (2016). Relationships among carbon emissions, economic growth, energy consumption and population growth: Testing Environmental Kuznets Curve hypothesis for Brazil, China, India and Indonesia. Ecological Indicators, 70, 466-479.

Etman, Omar, Osama Tolba, and Sherif Ezzeldin. "Double-Skin façades in Egypt between parametric and climatic approaches." (2013).

Chen, Jia-Yih, and Shao-Chu Huang. "Adaptive Building Facade Optimisation: An integrated Green-BIM approach." (2016).

Bacha, Cherif Ben, and Fatiha Bourbia. "Effect of kinetic facades on energy efficiency in office buildings-hot dry climates." 2016.

Ahmed, Mostafa MS, Ali K. Abdel-Rahman, Mahmoud Bady, and Essam Mahrous. "The thermal performance of residential building integrated with adaptive kinetic shading system." International Energy Journal 16, no. 3 (2016).

Elghazi, Yomna, Ayman Wagdy, and Sahar Abdalwahab. "Simulation driven design for kinetic system; optimize kaledocycle facade configuration for daylighting adequacy in hot arid climates." In Conference of International Building Performance Simulation Association, pp. 182-189. 2015.

Jayathissa, Prageeth, Jeremias Schmidli, Johannes Hofer, and A. Schlueter. "Energy performance of PV modules as adaptive building shading systems." EU PVSEC (2016): 2513-2517. 
Energy Reduction, Daylight and View Quality Assessment of a Passive Dynamic Facade in Hot Arid Climate

Climate of Phoenix Summary. (2014, August 05). Retrieved from https://azclimate.asu.edu/climate/climateofphoenix-summary/

2018 International Energy Conservation Code. (2017). Country Club Hills, IL: International Code Council.

Chalfoun, N. (2015). Fundamentals of Environmental Control Systems for Architectural Design of Buildings and Outdoor Spaces Revision 4.4. Tucson: University of Arizona House Energy Doctor.

Leather, Phil, Mike Pyrgas, Di Beale, and Claire Lawrence. "Windows in the workplace: Sunlight, view, and occupational stress." Environment and behavior 30, no. 6 (1998): 739-762. 